

\title{
Evolution of palladium sulfide phases during thermal treatments and consequences for acetylene hydrogenation
}

\author{
Yanan Liu, ${ }^{1,2}$ Alan J. McCue, ${ }^{2}$ Junting Feng, ${ }^{1 *}$ Shaoliang Guan, ${ }^{3}$ Dianqing $\mathrm{Li}^{1}$ and James A. \\ Anderson ${ }^{2 *}$ \\ ${ }^{1}$ State Key Laboratory of Chemical Engineering, Beijing University of Chemical Technology, \\ Beijing 100029, China. \\ ${ }^{2}$ Surface Chemistry and Catalysis Group, Materials and Chemical Engineering, Department \\ of Engineering, University of Aberdeen, Aberdeen, UK, AB24 3UE. \\ ${ }^{3}$ Cardiff Catalysis Institute, School of Chemistry, Cardiff University, Cardiff, UK, CF10 3AT \\ Tel: +44 1224 272838, Email: fengit@mail.buct.edu.cn; j.anderson@abdn.ac.uk
}

\begin{abstract}
Unsupported, bulk phase palladium sulfide has been studied for the selective hydrogenation of acetylene. The sample underwent significant change during thermal pretreatments, the extent of which depends on temperature. Exposure to hydrogen at temperatures of $150^{\circ} \mathrm{C}$ or above results in the loss of sulfur from the sample, primarily as hydrogen sulfide. As sulfur is lost, the sample is progressively transformed from a sulfur rich phase $(\mathrm{PdS})$ to a sulfur lean phase $\left(\mathrm{Pd}_{4} \mathrm{~S}\right)$ via an intermediate phase $\left(\mathrm{Pd}_{16} \mathrm{~S}_{7}\right)$. Reduction at $250^{\circ} \mathrm{C}$ produces a material, which contains simultaneously these three phases mentioned above with some $\mathrm{Pd}_{4} \mathrm{~S}$ phase is located at the surface, whereas reduction at $350^{\circ} \mathrm{C}$ results in a largely pure $\mathrm{Pd}_{4} \mathrm{~S}$ phase. Thermal treatments which produce a $\mathrm{Pd}_{4} \mathrm{~S}$ surface display excellent catalytic properties. At complete acetylene conversion at $250^{\circ} \mathrm{C}$, ethylene selectivites of $82.8 \%$ and $90.0 \%$ were obtained under non-competitive and competitive conditions, respectively. Beneficial catalytic properties arise from the uniformity of Pd sites due to the crystal structure of $\mathrm{Pd}_{4} \mathrm{~S}$ along with electronic influences on the adsorption/desorption processes arising from sulfur neighbours. No indications of deactivation or obvious deposition of carbon were observed over $\mathrm{Pd}_{4} \mathrm{~S}$ sample after $50 \mathrm{~h}$ on stream.
\end{abstract}

\section{Keywords}

Acetylene, ethylene, selective hydrogenation, palladium sulphide 


\section{Introduction}

A significant proportion of ethylene used for polymerisation is derived from naphtha cracking. This process results in an ethylene stream contaminated with $0.5-2 \%$ of acetylene, which can poison the polymerisation catalysts. ${ }^{[1,2,3]}$ To remove the impurity to an acceptable level $(<5 \mathrm{ppm})$, selective hydrogenation of acetylene is widely employed as it generates additional ethylene and therefore increases profitability. ${ }^{[4]}$ Thermodynamics makes this process viable ${ }^{[5]}$ when both acetylene and ethylene are present, since the adsorption energy of acetylene is generally greater on most surfaces than that of ethylene contributing to preferential adsorption. However, when acetylene concentration is low (i.e., near the $5 \mathrm{ppm}$ requirement), ethylene is free to adsorb resulting in over-hydrogenation to ethane, thereby decreasing process efficiency and profitability. Furthermore, acetylene based oligomerisation results in the formation of green oil $\left(\mathrm{C}_{x} \mathrm{H}_{y}\right)$, which accumulates on the catalyst surface leading to gradual deactivation. ${ }^{[1]}$ The extent to which deactivation occurs depends on plant design. A 'front-end' type reactor is situated upstream of the demethaniser, and the feed gas contains a large excess of hydrogen. In contrast, a 'back-end' type reactor uses a purified gas feed to which a near stoichiometric amount of hydrogen can be added. Deactivation is relatively rapid in hydrogen lean conditions resulting in the need to regenerate more frequently. ${ }^{[6]}$ Despite this limitation, back-end type reactors are the most common plant configuration. Industrial catalysts for this process generally contain $\mathrm{Pd}$ as the active component but require the use of $\mathrm{Ag}$ as a structural modifier ${ }^{[7]}$ with $\mathrm{CO}$ often used to compete with ethylene for adsorption sites to supress over-hydrogenation. ${ }^{[2]}$ Pd-based catalysts generally demonstrate high activity but limited selectivity in this reaction due to hydride/carbide formation ${ }^{[8,9,10,11,12,13]}$ with calculations suggesting that the barrier for ethylene desorption is higher than that for over-hydrogenation. ${ }^{[14]}$

A common approach to improve ethylene selectivity over Pd nanocatalysts is to alloy with a second metal such as $\mathrm{Ag}{ }^{[15,16,17]}, \mathrm{Au}^{[18,19]}, \mathrm{Cu}^{[20,21,22,23,24]}, \mathrm{Ni}^{[25]}$, and $\mathrm{Zn}^{[26]}$, which dilutes $\mathrm{Pd}$ and reduces the ensemble size, and thus inhibits formation of the $\beta$-PdH phase. ${ }^{[11]}$ In recent literature, the idea of 'Pd active site isolation' has become popular and typically contributes to enhanced alkene selectivity. ${ }^{[27]}$ Well defined intermetallic PdM compounds ( $\mathrm{M}=\mathrm{Ga}, \mathrm{In}, \mathrm{Cu}$ ) fall within this category and favour the enhancement of selectivity but at the expense of activity. ${ }^{[28,29,30]}$ Moreover, the effectiveness with which the costly precious metal component is used (i.e., fraction exposed at the surface) is generally low. Some progress has been made towards making nanosized intermetallic catalysts to overcome this limitation. ${ }^{[31]} \mathrm{A}$ more effective use of Pd has been demonstrated in single atom alloys (SAA's) where a high proportion of Pd atoms are actually surface atoms. In some cases the Pd atoms in SAA's are assigned as the active site, ${ }^{[32,33]}$ whereas in others they act as a site for hydrogen dissociation with 
spillover onto the alloy component where a selective reaction can take place. $\left[{ }^{34,35,36]}\right.$ There are also a growing number of reports which indicate that surface modifiers can influence selectivity in alkyne hydrogenation. In this regard, both sulphur ${ }^{[37,38,39]}$ and phosphorous ${ }^{[40,41,42]}$ containing compounds have been shown to be effective. Interestingly, with diphenyl sulfide as modifier, it was possible to decompose the organic component of the modifier, retain the sulfur atoms and still supress ethylene hydrogenation activity. ${ }^{[37]}$

Despite the surge in the number of approaches to enhance performance in alkyne hydrogenation, a number of challenges still remain, perhaps the most pertinent of which is enhanced resistance to deactivation. Therefore the search for improved catalyst formulations now extends beyond metal based catalysts with metal oxides such as $\mathrm{CeO}_{2}{ }^{[43,44]}$ and $\ln _{2} \mathrm{O}_{3}{ }^{[45]}$ showing promise, albeit at elevated temperature unless doped with other components. ${ }^{[46]}$ Recently, metal sulfides, or more specifically, supported palladium sulfide nanoparticles have been shown to be an excellent hydrogenation catalyst ${ }^{[47,48]}$ with performance attributed to the formation of the $\mathrm{Pd}_{4} \mathrm{~S}$ phase and isolation of the active $\mathrm{Pd}$ sites. ${ }^{[49,50]}$ Whilst these reports focused on a supported $\mathrm{Pd}_{4} \mathrm{~S}$ phase, it was hinted that similar results could be obtained with a bulk phase palladium sulfide powder. ${ }^{[49]}$ Reports of sulfur being beneficial in heterogeneous catalysis are still somewhat limited [51] Herein, results are presented which demonstrate how a PdS powder evolves and changes with thermal pre-treatment to yield a highly selective alkyne hydrogenation catalyst. Detailed characterisation by XRD, TPR, TEM, EDX, XPS and XAS create an understanding of how the phase composition and crystal structure impacts upon catalytic performance. The deposition of carbon over $\mathrm{Pd}_{4} \mathrm{~S}$ sample after $50 \mathrm{~h}$ reaction were investigated by TPO-MS. Whilst a bulk phase PdS powder does not represent an efficient use of the expensive Pd component, it does serve as an excellent material for creating links which reinforce our understanding of how and why supported sulfide phases are selective in alkyne hydrogenation.

\section{Experimental}

\section{Samples}

Palladium sulfide powder was purchased from Alfa-Aesar (12674, 99\% purity on a metal basis). Sample which was used as received is referred to as 'fresh palladium sulfide'. Portions of the as received sample were subjected to a reduction treatment in a $20 \% \mathrm{H}_{2} / \mathrm{N}_{2}$ mixture $\left(200 \mathrm{ml} \mathrm{min}^{-1}\right)$ for $1 \mathrm{~h}$ at 50 , 150,250 or $350^{\circ} \mathrm{C}$ in the reactor. Samples are denoted as R50, R150, R250 or R350 to reflect the reduction temperature.

\section{Catalyst testing}

Gas phase hydrogenation reactions were performed in a continuous flow, fixed-bed microreactor ( 9 $\mathrm{mm}$ diameter, Microactivity Reference, supplied by Micromeritics) using catalyst ( $20 \mathrm{mg}$ ) diluted with 
silicon carbide (Aldrich, 200-450 mesh). Single reagent tests were conducted with a mixture of $1.2 \%$ acetylene/balance $\mathrm{N}_{2}$ with 2 equivalents of $\mathrm{H}_{2}$ co-fed relative to acetylene. Multi reagent tests were conducted in a mixture of $0.6 \%$ acetylene/5.4\% ethylene/balance $\mathrm{N}_{2}$ flow with 2 equivalents of $\mathrm{H}_{2}$ cofed relative to acetylene and a space velocity of $800,000 \mathrm{~h}^{-1}$ based on mass of catalyst. In a typical experiment, a catalyst was tested in the temperature range $50-250^{\circ} \mathrm{C}$ with $25^{\circ} \mathrm{C}$ increments with $5 \mathrm{~h}$ time on stream (TOS) at each temperature to ensure quantitative measurement of raw conversion/selectivity data reproducibility.

The gas composition at the reactor outlet was determined by GC-FID (PE Clarus 580) using an elite alumina capillary column. Conversion was calculated as the amount of acetylene reacted divided by the amount introduced. Selectivity to ethylene and ethane were calculated as the amount formed (i.e., ethylene out - ethylene in) divided by the amount of acetylene reacted. For multi reagent tests a negative ethylene selectivity implies that a fraction of the ethylene co-fed to the reactor also undergoes hydrogenation to ethane. Acetylene is known to form oligomers under reaction conditions. Whilst analysis permitted detection of $\mathrm{C} 4$ and $\mathrm{C} 6$ products, it was deemed more appropriate to evaluate oligomer selectivity based on a carbon balance ${ }^{[6]}$, since higher molecular weight oligomers may remain adsorbed on the surface, as measured by TPO-MS.

\section{Characterisation}

Surface area of samples was measured using a Micromertics Tristar 3000 instrument using $\mathrm{N}_{2}$ as adsorbate. Samples were first pre-treated by heating to $200^{\circ} \mathrm{C}$ for $2 \mathrm{~h}$ in a flow of $\mathrm{N}_{2}$. X-Ray Diffraction (XRD) patterns of samples were measured in the range of $2 \theta=20-85^{\circ}$ using an $X^{\prime}$ Pert powder diffractometer (PANalytical) fitted with a PIXcel1D detector, using $\mathrm{Cu}$ Ka radiation and a step size of $0.013^{\circ}$ ( $\approx 15 \mathrm{~min}$ acquisition time). The phase compositions were determined by Rietveld refinement using the software HighScore Plus. ${ }^{[52]}$

Temperature programmed experiments were conducted using a TPDRO 1100 instrument with a TCD detector. The effluent gas stream was then passed into an Eco-Sys portable mass spectrometer (European Spectrometry Services) to determine the gas composition. Temperature programmed reduction (TPR) was conducted by heating a fresh palladium sulfide sample in the temperature range $40-350^{\circ} \mathrm{C}$ using a heating rate of $5^{\circ} \mathrm{C} \mathrm{min}^{-1}$ in a mixture of $5 \% \mathrm{H}_{2} / \mathrm{N}_{2}$. Temperature programmed desorption (TPD) was conducted by first performing a TPR to $150^{\circ} \mathrm{C}$, followed by cooling to $40^{\circ} \mathrm{C}$ in the same $5 \% \mathrm{H}_{2} / \mathrm{N}_{2}$ mixture. The gas was then switched to $\mathrm{N}_{2}$ and sample heated from 40 to $350^{\circ} \mathrm{C}$ using a heating rate of $5{ }^{\circ} \mathrm{C} \mathrm{min}{ }^{-1}$. TPR and TPD results are presented per gram of sample and hydrogen consumption quantified based on a response factor determined using a $\mathrm{CuO}$ standard. Temperature 
programmed oxidation (TPO) in $5 \% \mathrm{O}_{2} / \mathrm{He}$ at the temperature range $40-500^{\circ} \mathrm{C}$ using a ramping rate of $5{ }^{\circ} \mathrm{C} \mathrm{min}^{-1}$ was performed over used samples.

High Resolution Transmission Electron Microscopy (HR-TEM) images were collected using a JEOL JEM2100 instrument. The particle size and lattice fringes were characterised by analysis of the collected images. The morphology, structure and elemental composition of the samples were examined in several zones using a Zeiss Supra 55 Scanning Electron Microscope (SEM) equipped with an energy dispersive X-ray (EDX) analyser.

X-Ray Photoelectron Spectroscopy (XPS) of samples was performed using a Thermo Fisher Scientific $\mathrm{K}$-alpha ${ }^{+}$spectrometer. Samples were analysed using a micro-focused monochromatic AI X-ray source (72 W) over an area of approximately 400 microns. Data were recorded at pass energies of $150 \mathrm{eV}$ for survey scans and $40 \mathrm{eV}$ for high resolution scan with $1 \mathrm{eV}$ and $0.1 \mathrm{eV}$ step sizes respectively. Charge neutralisation was achieved using a combination of low energy electrons and argon ions. The resulting spectra were analysed using CasaXPS peak fitting software and sample charging corrected using the $C$ $1 \mathrm{~s}$ signal at $284.8 \mathrm{eV}$ as reference.

The Pd and S edge X-ray adsorption spectra (XAS) were collected on the B18 beamline at the Diamond Light Source (Harwell, UK). Measurements of Pd edge XAS were performed using a QEXAFS set-up with a fast scanning Si (311) double crystal monochromator (0.35 eV step size). Samples were diluted with cellulose to optimise the effective edge step for X-ray absorption fine structure (XAFS), pressed into pellets and measured in transmission mode using ion chamber detectors. For fresh palladium sulfide, an average of ten scans were obtained to provide a suitable signal to noise ratio. For the R350 sample, an average of five scans produced suitable signal to noise. All Pd edge XAS spectra were collected concurrently with the appropriate foil placed between ion detectors $I_{t}$ and $I_{\text {ref. }} S$ K-edge XAFS measurements were tested in fluorescence mode using a QEXAFS setup with fast scanning Si (111) double crystal monochromator. Data were collected using a 4-element Vortex Silicon Drift fluorescence detector in the soft X-ray experimental chamber at room temperature. 5 scans per sample were measured with $k_{\max }=9$, and sulfur fluoride was used as the standard for $S$ edge EXAFS analysis. XAS data processing was performed using IFEFFIT 19 with the Horae package (i.e., Athena and Artemis). A fixed input value for the amplitude reduction factor ( $\mathrm{S} 02$ ) of 0.85 was chosen based on a known reference material.

\section{Results}

Selective hydrogenation of acetylene under competitive and non-competitive conditions 
The catalytic behaviour of palladium sulfide reduced at four different temperatures was first evaluated using a simple acetylene/hydrogen mixture with results displayed in Figure 1. Note that for each sample, the reaction began with a period at $50^{\circ} \mathrm{C}$, prior to increasing the reaction temperature sequentially in $25^{\circ} \mathrm{C}$ increments up to $250^{\circ} \mathrm{C}$ (5h TOS permitted at each temperature). Several observations can be made by first focusing on the data collected at reaction temperature of $50^{\circ} \mathrm{C}$. Performance changes markedly with TOS for R50, R150 and R250 samples, whereas R350 sample appears far more stable. This may be because samples reduced at lower temperature undergo physical change during time on stream (see later). With regards to the initial activity, there is a clear trend between reduction temperature and acetylene conversion with activity increasing in the following order: R350 > R250 > R150 > R50, suggesting differences in structure for PdS samples reduced at these four different temperatures. In terms of selectivity, all samples produce ethylene as the major product with higher selectivity observed for samples which showed lower activity. As temperature was increased in the range $75-175^{\circ} \mathrm{C}$, the samples showed marked differences. R50 exhibits low selectivity to ethane and higher selectivity to oligomers, whereas R150, R250 and R350 tend to produce more ethane than oligomers. Once the reaction temperature reached $200^{\circ} \mathrm{C}$, all samples produce similar product distributions, which suggests that samples are structurally and physically similar. Interestingly, ethylene selectivity appears to reach a plateau for all samples with only lesser amounts of ethane and oligomers formed beyond $200^{\circ} \mathrm{C}$. For example, at $250^{\circ} \mathrm{C}$, R350 displays a maximum selectivity of $82.8 \%$ with little ethane $(9.5 \%)$ and oligomers (7.7\%). These findings would suggest that treatment at higher temperature, either in reaction or by pre-reduction, is conducive to producing a more selective alkyne hydrogenation catalyst.
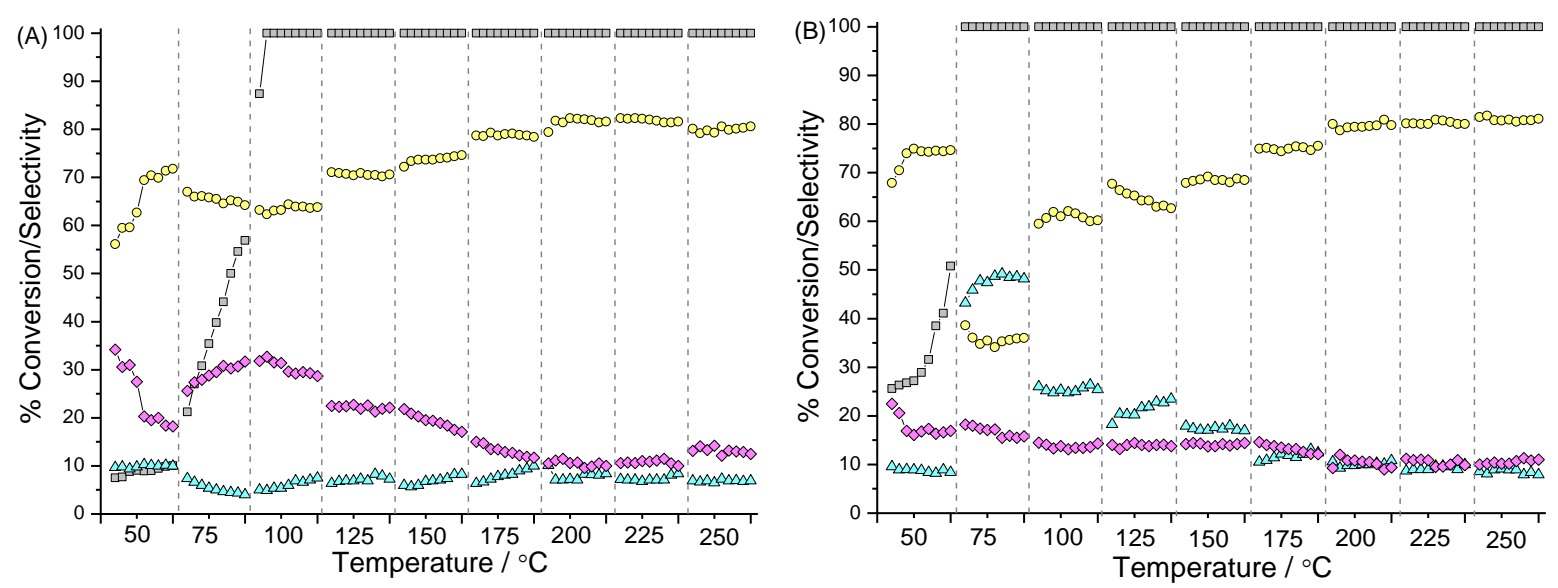

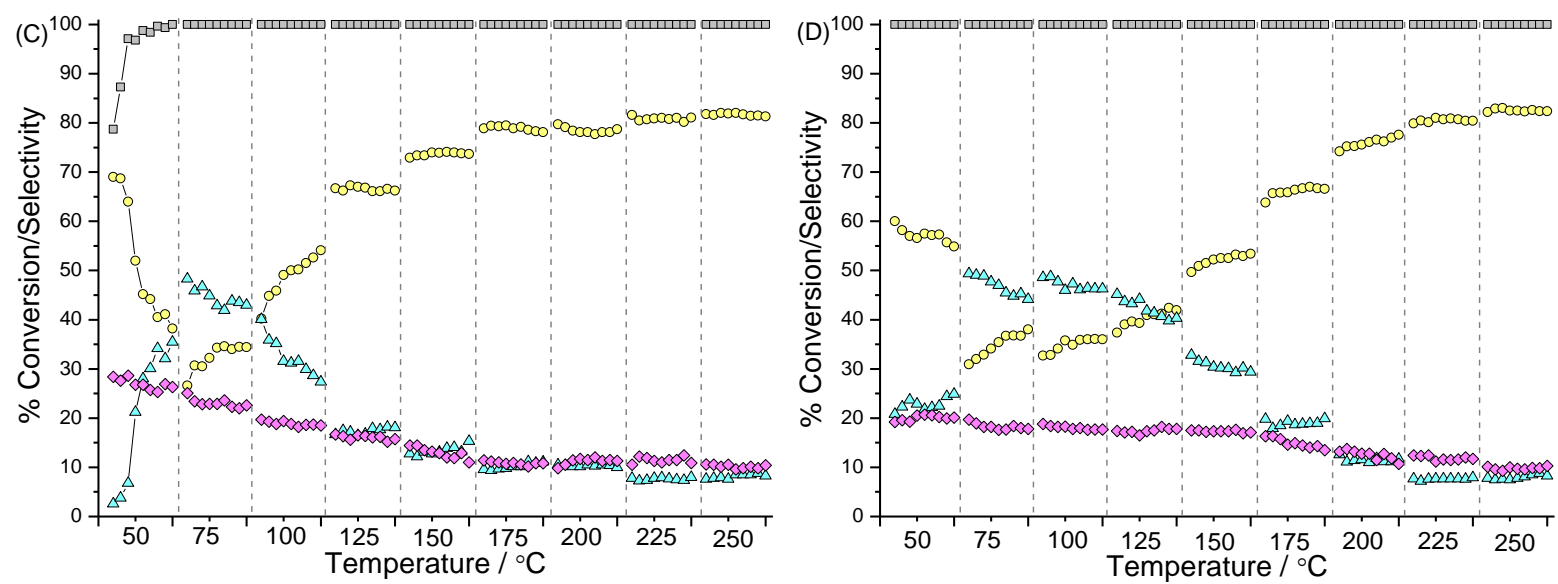

Figure 1. Acetylene conversion (grey squares) and product selectivity to ethylene (yellow circles), ethane (cyan triangles) and oligomers (pink diamonds) as a function of temperature. Data points at each temperature correspond to $5 \mathrm{~h}$ time on stream in order to ensure quantitative measurement of raw conversion/selectivity data reproducibility. (A) R50, (B) R150, (C) R250 and (D) R350 (1 bar, 2-fold excess of $\mathrm{H}, \mathrm{SV}=800,000 \mathrm{~h}^{-1}$, in the acetylene/hydrogen feed).

R350 sample was selected for further testing on the basis of characterisation results (see later), since links between structural properties and catalytic performance could be readily determined. Catalytic results obtained under competitive conditions (i.e., both acetylene and ethylene present in the feed gas), more akin to those encountered in industry ${ }^{[6]}$ are summarised in Table 1 . It is important to highlight a few points. Firstly, a negative ethylene selectivity implies that a fraction of the ethylene present in the feed gas has undergone hydrogenation. Secondly, at all temperatures, $100 \%$ conversion of acetylene was observed, despite the use of a space velocity 2 orders of magnitude higher than that typically used in industry. ${ }^{[6]}$ This does, in a qualitative sense, suggest that R350 is highly active. Quoting performance at complete conversion is important because industrially, approximately $99.95 \%$ acetylene conversion is necessary to reach the requisite ethylene purity. In addition, selectivity at lower conversion may reflect thermodynamic selectivity (i.e., acetylene adsorbs more strongly than ethylene) as opposed to whether or not a catalyst is truly selective. In agreement with simple acetylene/hydrogen tests, R350 sample produces significant amounts of ethane at low reaction temperatures (Table 1). However, over-hydrogenation decreases significantly at $200^{\circ} \mathrm{C}$ with ethylene becoming the major product. At $250^{\circ} \mathrm{C}$, ethylene selectivity of $90 \%$ was obtained, which compares well with state of the art materials such as ceria ( $81 \%$ ethylene selectivity at $86 \%$ acetylene conversion $250^{\circ} \mathrm{C}, 30$ fold excess of $\left.\mathrm{H}_{2}\right)$, indium oxide ( $\approx 90 \%$ ethylene selectivity @ $30 \%$ conversion $-350^{\circ} \mathrm{C}, 30$ fold excess of $\mathrm{H}_{2}$ ) and monometallic Pd catalysts (Table S1). ${ }^{[43,46,53,54,55]}$ 
Table 1. Acetylene conversion and product selectivity to ethylene and ethane at different reaction temperatures over R350 sample ${ }^{a}$

\begin{tabular}{|c|c|c|c|c|}
\hline Performances & $100^{\circ} \mathrm{C}$ & $150^{\circ} \mathrm{C}$ & $200^{\circ} \mathrm{C}$ & $250^{\circ} \mathrm{C}$ \\
\hline $\begin{array}{l}\text { Conversion of acetylene } \\
(\%)\end{array}$ & 100 & 100 & 100 & 100 \\
\hline $\begin{array}{l}\text { Selectivity to ethylene } \\
\text { (\%) }\end{array}$ & $-17.2^{b}$ & $-1.1^{a}$ & 54.4 & 90.9 \\
\hline Selectivity to ethane (\%) & 96.7 & 98.1 & 45.6 & 9.1 \\
\hline $\begin{array}{l}\text { Selectivity to oligomer } \\
\qquad(\%)^{c}\end{array}$ & 20.5 & 3.0 & 0 & 0 \\
\hline
\end{tabular}

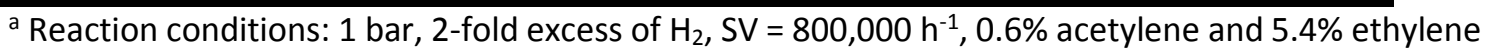
in feed gas.

${ }^{b}$ Note that a negative selectivity to ethylene implies that a fraction of ethylene present in the feed gas was hydrogenated.

c Oligomer selectivity including C4 and C6 products was evaluated based on a carbon balance (100 $\pm 2 \%$ ). Carbon contents of higher molecular weight oligomers which may remain adsorbed on the catalysts were $1.7 \mathrm{wt}$ \%, measured by TPO-MS.
}

\section{Hydrogen consumption during reduction.}

Figure $2 \mathrm{~A}$ shows the $\mathrm{H}_{2}$-TPR profile (top) of fresh palladium sulfide sample along with the corresponding MS profile of gas phase species (bottom). A strong peak in the temperature range 30$150^{\circ} \mathrm{C}$ was observed due to hydrogen consumption. This is consistent with the MS profile which shows a decrease in ion intensity associated with $\mathrm{H}_{2}(\mathrm{~m} / \mathrm{z}=2)$. Quantification of this peak suggests that 1.04 mmol of $\mathrm{H}_{2}$ is consumed per gram of sample which equates to a $\mathrm{H}_{2}$ : PdS ratio of 0.15 . At ca. $175^{\circ} \mathrm{C}, \mathrm{a}$ negative peak was observed. Based on relative thermal conductivities, a negative peak would normally be associated with release of $\mathrm{H}_{2}$ from a sample during a TPR. However, the corresponding MS profile suggests that small amounts of $\mathrm{H}_{2} \mathrm{~S}(\mathrm{~m} / \mathrm{z}=34), \mathrm{SO}_{2}(\mathrm{~m} / \mathrm{z}=64)$ and $\mathrm{H}_{2} \mathrm{O}(\mathrm{m} / \mathrm{z}=18)$ are also released. With all three of these gases, a positive peak would be expected from the TCD detector using $\mathrm{N}_{2}$ as carrier gas. The net effect would be that the magnitude of the signal associated with $\mathrm{H}_{2}$ release at $c a$. $175^{\circ} \mathrm{C}$ is hidden. To separate out these effects, a sample was exposed to $\mathrm{H}_{2}$ up to $150^{\circ} \mathrm{C}$ before being cooled down to $40^{\circ} \mathrm{C}$ and a $\mathrm{N}_{2}$-TPD performed. In this case, a much larger negative peak was observed (Figure 2B-top) along with a sharp MS signal associated with $\mathrm{H}_{2}$ and small amounts of $\mathrm{SO}_{2}$ and $\mathrm{H}_{2} \mathrm{O}$ (Figure 2B-bottom). Comparison of the peak area of the negative peak in Figures $2 \mathrm{~A}$ and $2 \mathrm{~B}$ show that in the latter case, the peak was almost 5 times larger. This would appear to be consistent with the interpretation that in Figure 2A, the peak is a composite of all the gases being released. Returning to the $\mathrm{H}_{2}$-TPR (Figure 2A), as temperature was increased beyond $225^{\circ} \mathrm{C}$, a sharp increase in the MS signal 
associated with $\mathrm{H}_{2} \mathrm{~S}$ was observed. There was no hydrogen consumption at this point, suggesting that $\mathrm{H}_{2} \mathrm{~S}$ was formed from hydrogen consumed at lower temperature and stored in the material until a critical temperature for desorption had been reached. However, were that the case, $\mathrm{H}_{2} \mathrm{~S}$ should be observed at higher temperature in Figure $2 \mathrm{~B}$. Since no $\mathrm{H}_{2} \mathrm{~S}$ was detectable at any point during $\mathrm{N}_{2}-\mathrm{TPD}$ it is likely that $\mathrm{H}_{2} \mathrm{~S}$ is predominantly formed at temperatures above $225^{\circ} \mathrm{C}$.
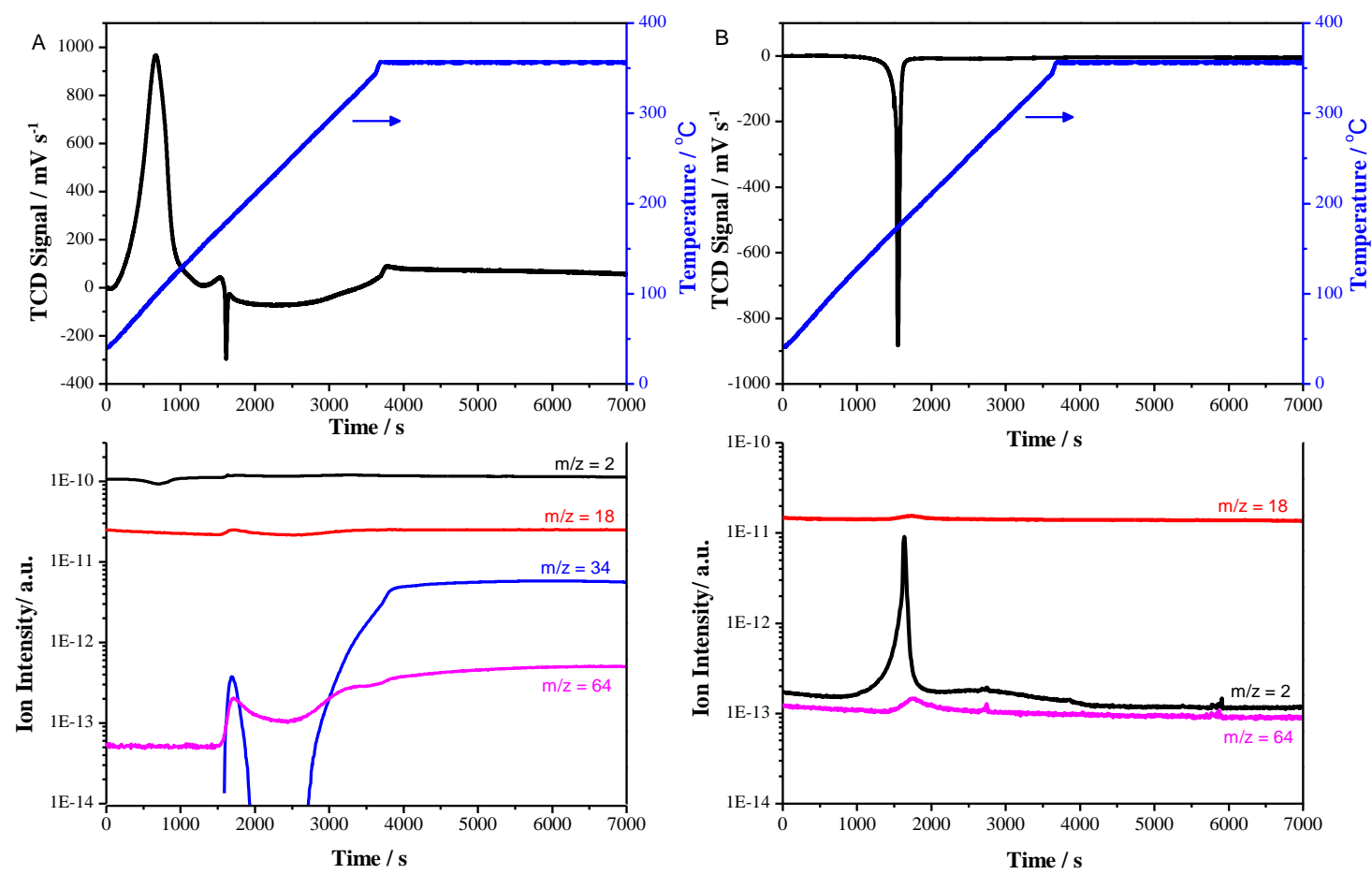

Figure 2. (A) TPR profile (top) and corresponding MS profile (bottom) for fresh palladium sulphide sample. (B) TPD profile (top) and corresponding MS profile (bottom) for sample heated to $150^{\circ} \mathrm{C}$ in $5 \%$ $\mathrm{H}_{2} / \mathrm{N}_{2}$ and cooled before $\mathrm{N}_{2}$ TPD. $\mathrm{m} / \mathrm{z}$ ratios of 2, 18, 34 and 64 are attributed to $\mathrm{H}_{2}, \mathrm{H}_{2} \mathrm{O}, \mathrm{H}_{2} \mathrm{~S}$ and $\mathrm{SO}_{2}$, respectively.

\section{Phase composition following reduction}

Based on TPR experiments, it is expected that the composition of samples will change depending on pre-reduction temperature. As well as this, it is known that palladium sulfide can exist ${ }^{[56]}$ in a number of different phases including $\mathrm{PdS}, \mathrm{Pd}_{16} \mathrm{~S}_{7}$ and $\mathrm{Pd}_{4} \mathrm{~S}$ (note that transformation from $\mathrm{PdS} \rightarrow \mathrm{Pd}_{16} \mathrm{~S}_{7} \rightarrow \mathrm{Pd}_{4} \mathrm{~S}$, samples gradually become increasingly palladium rich). In order to investigate if and how phase composition changed with reduction temperature, a detailed XRD study was performed. Diffraction patterns for sample reduced at different temperatures are presented in Figure 3 along with reference patterns for the most common palladium sulfide phases. No discernible features were observed in the pattern of R50, or that of fresh palladium sulfide (not shown), suggesting that both materials are amorphous. In general, increasing the pre-reduction temperature resulted in materials which were 
more crystalline and this was accompanied by particle growth (TEM data discussed later). Reduction at $150^{\circ} \mathrm{C}$ results in the emergence of peaks at $2 \theta=30.3^{\circ}, 31.07^{\circ}, 33.95^{\circ}$, which were roughly in agreement with the standard PdS (PDF 25-1234). In order to further quantitatively analyse the phase compositions of four reduced materials, Rietveld refinements were carried out based on the structural models $\left(P 4_{2} / m, P \overline{4} 2_{1} C\right.$ and $\left.I \overline{4} 3 m\right),{ }^{[52]}$ and the results are listed in Table 2. Generally, small reliability factors $(R<2 \%)$ were determined, which indicates that these refinements were satisfactory. For R150 sample, the refinement fit was poorer but suggested that the refined weight percent of PdS phase was 48.6 wt. \%, along with the presence of a larger amount of $\mathrm{Pd}_{16} \mathrm{~S}_{7}$ (51.4 wt. \%). A far more defined pattern was observed for R250 sample (Figure 3) and refinement suggested a shift towards palladium rich phases (Table 2) consistent with loss of sulfur observed at higher temperature during $\mathrm{H}_{2}$-TPR (Figure 2). Perhaps unsurprisingly, this trend continued for R350 sample which can be considered as a largely pure phase $\mathrm{Pd}_{4} \mathrm{~S}$ (94.6\% refined weight percent). Based on XRD, the following phase transformation with increasing reduction temperature can be expected:

$$
\text { Amorphous palladium sulfide } \rightarrow \mathrm{PdS} \rightarrow \mathrm{Pd}_{16} \mathrm{~S}_{7} \rightarrow \mathrm{Pd}_{4} \mathrm{~S}
$$

As the change in phase composition appears to be largely controlled by temperature in the presence of $\mathrm{H}_{2}$, it is expected that both R50 and R150 samples would be liable to undergo phase changes during catalytic reaction (i.e., as the temperature is increased beyond the pre-reduction temperature). In contrast, R250 and in particular R350 should be far more stable, which explains why their reactivity trends appear similar (Figure 1). In order to validate this hypothesis, the XRD pattern of used R250 and R350 samples were further collected. After subtraction of the SiC diluent contribution, the XRD pattern looked identical to the fresh samples, confirming no further phase change occurred (Figure S1). 


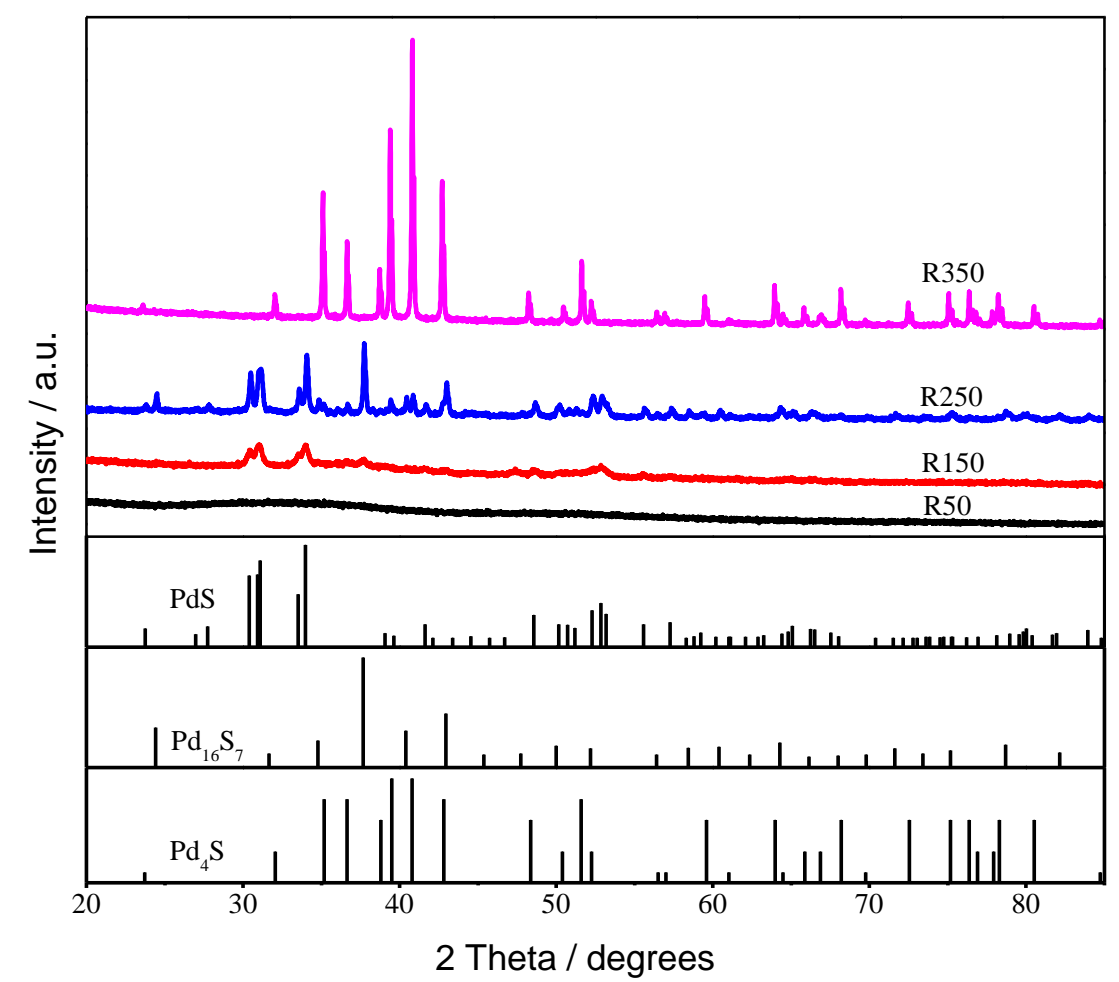

Figure 3. XRD patterns of R50, R150, R250 and R350 samples. Reference patterns for XRD patterns for PdS, $\mathrm{Pd}_{16} \mathrm{~S}_{7}$ and $\mathrm{Pd}_{4} \mathrm{~S}$ are included.

Table 2. Composition of palladium sulfide samples determined by XRD, EDX and XPS.

\begin{tabular}{|c|c|c|c|c|c|c|c|c|c|c|c|}
\hline \multirow{2}{*}{ Sample } & \multirow{2}{*}{$\begin{array}{c}\text { BET } \\
\text { surface } \\
\text { area } \\
\left(\mathrm{m}^{2} \mathrm{~g}^{-1}\right)\end{array}$} & \multicolumn{3}{|c|}{$\begin{array}{c}\text { XRD phase } \\
\text { composition }^{\text {a }}\end{array}$} & \multicolumn{2}{|c|}{ XRD composition } & \multicolumn{2}{|c|}{ EDX composition } & \multirow{2}{*}{$\begin{array}{l}\text { Bulk } \\
\text { phase } \\
\text { Pd:S } \\
\text { ratio }^{b}\end{array}$} & \multirow{2}{*}{$\begin{array}{c}\text { Bulk } \\
\text { phase } \\
\text { Pd } \\
\text { loading } \\
\text { (wt. \%) }\end{array}$} & \multirow{2}{*}{$\begin{array}{c}\text { Surface } \\
\text { Pd:S } \\
\text { ratio }^{d}\end{array}$} \\
\hline & & PdS & $\mathrm{Pd}_{16} \mathrm{~S}_{7}$ & $\mathrm{Pd}_{4} \mathrm{~S}$ & $\begin{array}{c}\text { Pd } \\
\text { (wt. \%) }\end{array}$ & $\begin{array}{c}\text { S } \\
\text { (wt. \%) }\end{array}$ & $\begin{array}{c}\text { Pd } \\
\text { (wt. \%) }\end{array}$ & $\begin{array}{c}\text { S } \\
\text { (wt. \%) }\end{array}$ & & & \\
\hline R50 & 20.7 & - & - & - & - & - & 79.9 & 20.1 & 1.2 & 75.9 & 1.0 \\
\hline R150 & 19.7 & 48.6 & 51.4 & 0.0 & 82.7 & 17.3 & 83.1 & 16.9 & 1.5 & 81.3 & 1.0 \\
\hline R250 & 3.6 & 27.4 & 58.2 & 14.4 & 85.7 & 14.3 & 85.3 & 14.7 & 1.8 & 83.6 & 1.6 \\
\hline R350 & 1.5 & 5.4 & 0.0 & 94.6 & 92.1 & 7.9 & 92.5 & 7.5 & 3.1 & 90.2 & 3.0 \\
\hline
\end{tabular}

a Determined by XRD

${ }^{b}$ Determined by EDX

${ }^{c}$ Determined by ICP

${ }^{\mathrm{d}}$ Determined by XPS

\section{Microscopy study following reduction}

The micro-structure of PdS nanoparticles reduced at 50,150, 250 and $350^{\circ} \mathrm{C}$, were evaluated by HRTEM (Figure 4). Sample subjected to reduction at $50^{\circ} \mathrm{C}$ shows a very small particle size (Figure $4-\mathrm{A}_{1}$ 
and $A_{2}$ ) and appears largely amorphous at high magnification (Figure $4-A_{3}$ and $A_{4}$ ), consistent with XRD measurements (Figure 3). In comparison, R150 sample appears to have undergone agglomeration resulting in increased particle sizes (Figure $4-B_{1}$ ). In agreement with expectations based on XRD measurements, R150 sample exhibits lattice fringes which may be attributed to both PdS (Figure 4$\mathrm{B}_{4}$ ) and $\mathrm{Pd}_{16} \mathrm{~S}_{7}$ (Figure $4-\mathrm{B}_{3}$ ) phases. Increasing the reduction temperature to 250 or $350^{\circ} \mathrm{C}$ further increased the crystallinity and particle size (Figure 4-C and D), and this latter aspect can be clearly seen in the diminished BET surface areas (Table 2). With the R250 sample, lattice fringes were observed which can be attributed to multiple palladium sulfide phases (Figure $4-C_{3}$ and $C_{4}$ ). Consistent with XRD measurements, the predominant lattice fringes for $R 350$ sample are associated with the $\mathrm{Pd}_{4} \mathrm{~S}$ phase (i.e., $d=0.228 \mathrm{~nm},(210)$-Figure $4-\mathrm{D}_{4}$ ).

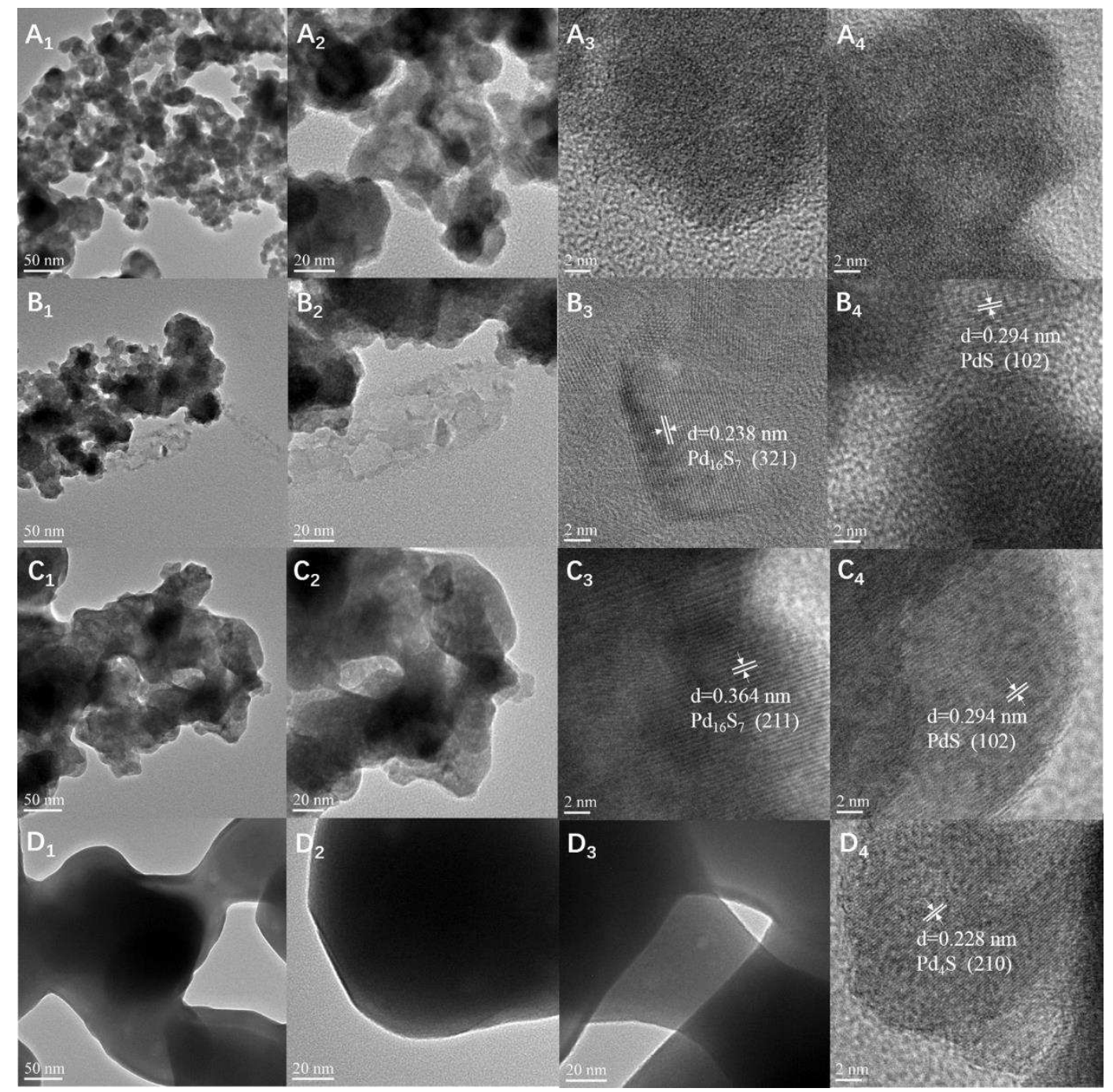

Figure 4. HRTEM images of (A) R50, (B) R150, (C) R250 and (D) R350. 
In order to assess sample uniformity, EDX mapping was performed in several zones to ensure analyses were representative of the whole sample (Figure 5 and Figure S2). As observed with TEM, increasing pre-reduction temperature tends to result in agglomeration of the palladium sulfide. The insets of Figure 5 illustrate the elemental mapping scan of all four samples and the images demonstrate a homogeneous distribution of $\mathrm{Pd}$ and $\mathrm{S}$ elements across the particles. Therefore, whilst there is evidence from XRD and TEM that the phase of each individual particle may be different, it would appear unlikely that there are particles which are exclusively composed of either palladium or sulfur. The weight percent of palladium and sulfur was measured from EDX and is presented in Table 2 and S2. As expected, as reduction temperature is increased, the samples become richer in palladium as a result of the loss of sulfur (Figure 2). For example, R50 sample is composed of 20.1 wt. \% sulfur which decreases to 16.9 and 14.7 wt. \% for R150 and R250 samples, respectively. Interestingly, there is a noticeable decrease in the amount of sulfur upon going from R250 to R350, in-spite of relatively little change to catalytic performance (compare Figure $1 \mathrm{c}$ and d). Similar catalytic performance would indicate that the surface structure/composition is likely to be similar. As a result, it is thought the additional loss of sulfur with heating to $350^{\circ} \mathrm{C}$ is associated with loss from the bulk of particles as opposed to the surface. Based on the phase composition determined from XRD, the corresponding Pd and S weight percent was calculated for R150, R250 and R350 samples (it was not possible to calculate for the amorphous R50). Excellent agreement was obtained between the composition determined by XRD, EDX and ICP (Table 2), confirming both techniques give complimentary information for these samples.
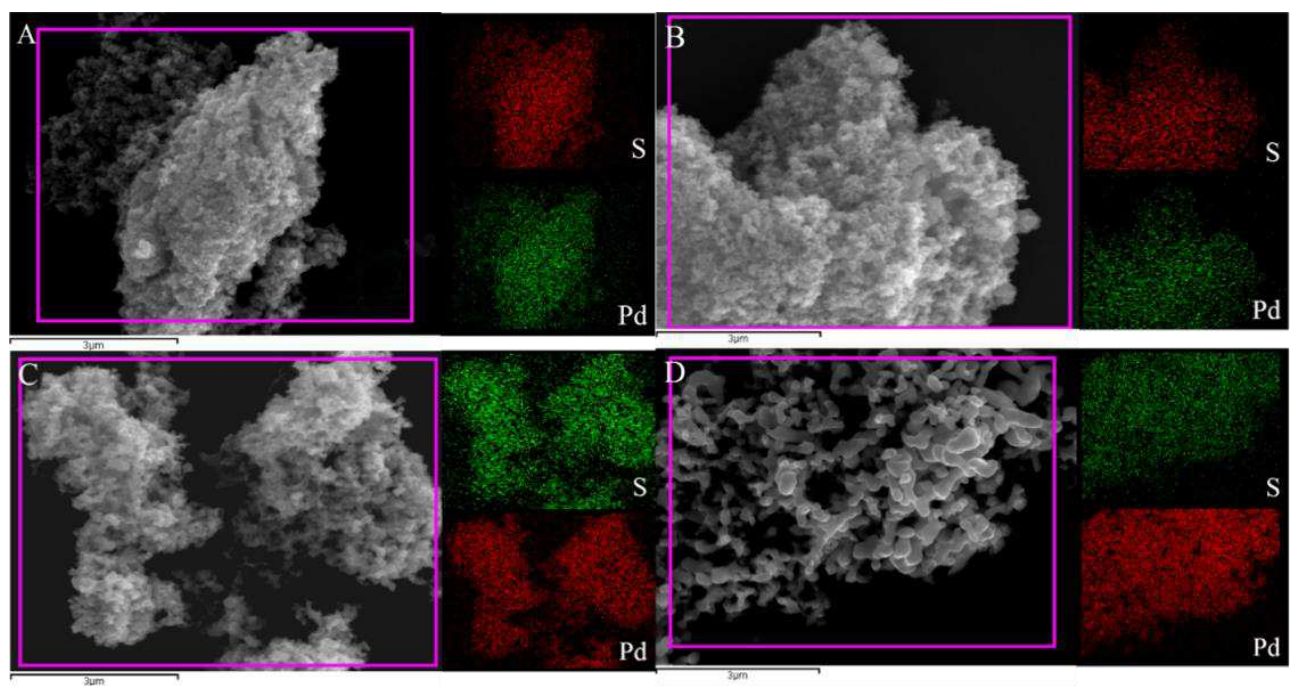

Figure 5. SEM-EDX images of (A) R50, (B) R150, (C) R250 and (D) R350. The insets show the S (green) and $\mathrm{Pd}(\mathrm{red})$ elemental mapping of the area within the pink square. 


\section{Surface composition following reduction}

Whilst XRD, TEM and EDX measurements were all in agreement, they largely provide insight into the bulk structure which may or may not be the same as the surface. Therefore, in order to obtain information specific to the surface and near surface region, XPS measurements were collected (Figure 6). The doublet $P d 3 d_{5 / 2}$ and $3 d_{3 / 2}$ of fresh PdS appear at 336.8 and $342.0 \mathrm{eV}$, respectively, suggesting that only $\mathrm{Pd}^{2+}$ exists. With the reduction temperature increasing, it is noticed that the $\mathrm{Pd} 3 \mathrm{~d}_{5 / 2}$ peak shifts from $336.8 \mathrm{eV}$ (in R50) to $335.5 \mathrm{eV}$ for the reduced catalyst at $350{ }^{\circ} \mathrm{C}$. Given that reduced palladium shows a $3 d_{5 / 2}$ peak near $335.2 \mathrm{eV}$ and the equivalent peak in palladium oxide occurs at $c a$ $336.7 \mathrm{eV}$, it is possible to make comment regarding the oxidation state of $\mathrm{Pd}$ in palladium sulfide. For example, reduction at low temperature results in $\mathrm{Pd}$ atoms retaining a more positive formal charge, whereas reduction at $350^{\circ} \mathrm{C}$ sees $\mathrm{Pd}$ atoms with a near neutral charge. This observation is logical since in ' $\mathrm{PdS}$ ' the formal charge of $\mathrm{Pd}$ would be +2 , whereas in ' $\mathrm{Pd}_{4} \mathrm{~S}$ ' the formal charge would be +0.5 (assuming $\mathrm{S}^{2-}$ in both cases). The shift is also in agreement with literature. Bachiller-Baeza et al. ${ }^{[47]}$ reported that $\mathrm{PdSO}_{4}$ impregnated on a carbon support produced a shift in the $\mathrm{Pd} 3 \mathrm{~d}_{5 / 2}$ peak from 337.3 to $335.5 \mathrm{eV}$ during a reduction treatment, which formed $\mathrm{Pd}_{4} \mathrm{~S}$.

The $S 2 p_{3 / 2}$ region (Figure $6 B$ ) of fresh PdS, R50, R150 and R250 shows a clear signal, while the peaks in R350 sample exhibit lower intensity since this contains the smallest amount of sulfur after thermal treatment (see Table 2). The sulfur peak for fresh PdS and samples reduced at 50,150 and $250{ }^{\circ} \mathrm{C}$ is very broad (160-164 eV), implying it may be composed of more than one component. Typically, the $2 p_{3 / 2}$ peak for a sulfide like species is observed at $161.5 \mathrm{eV}{ }^{[57]}$ and overlap between the $2 p_{3 / 2}$ and $2 p_{1 / 2}$ can result in a broad, unresolved doublet. In contrast, an analogous metal sulfate would exhibit a peak at $169 \mathrm{eV} .{ }^{[47]}$ It is therefore likely that the broad peak observed in the XP spectrum of fresh PdS, R50, R150 and R250 is an unresolved doublet associated with a sulfide peak. However interestingly, the binding energy of broad peak observed in R350 is between 162-166 eV, which was also similar with that reported by Singh et al. ${ }^{[58]}$. In that case, the authors did not attribute the signal to a sulfide species as such, but opted to describe the $\mathrm{Pd}_{4} \mathrm{~S}$ structure as an 'alloy type compound'. Based on the spectra presented in this work, it appears reasonable to assume that some formal charge exists on the Pd and $\mathrm{S}$ atoms (i.e., the binding energy of $\mathrm{Pd}$ is similar with the expected for $\mathrm{Pd}^{0}$ and the binding energy for $\mathrm{S}$ is higher than $\mathrm{S}^{2-}$ ). Table 2 also shows the surface Pd:S ratio as determined by XPS along with the bulk phase ratio determined from EDX. There is a rough agreement between the two methods suggesting that the bulk phase and surface are closely related. 

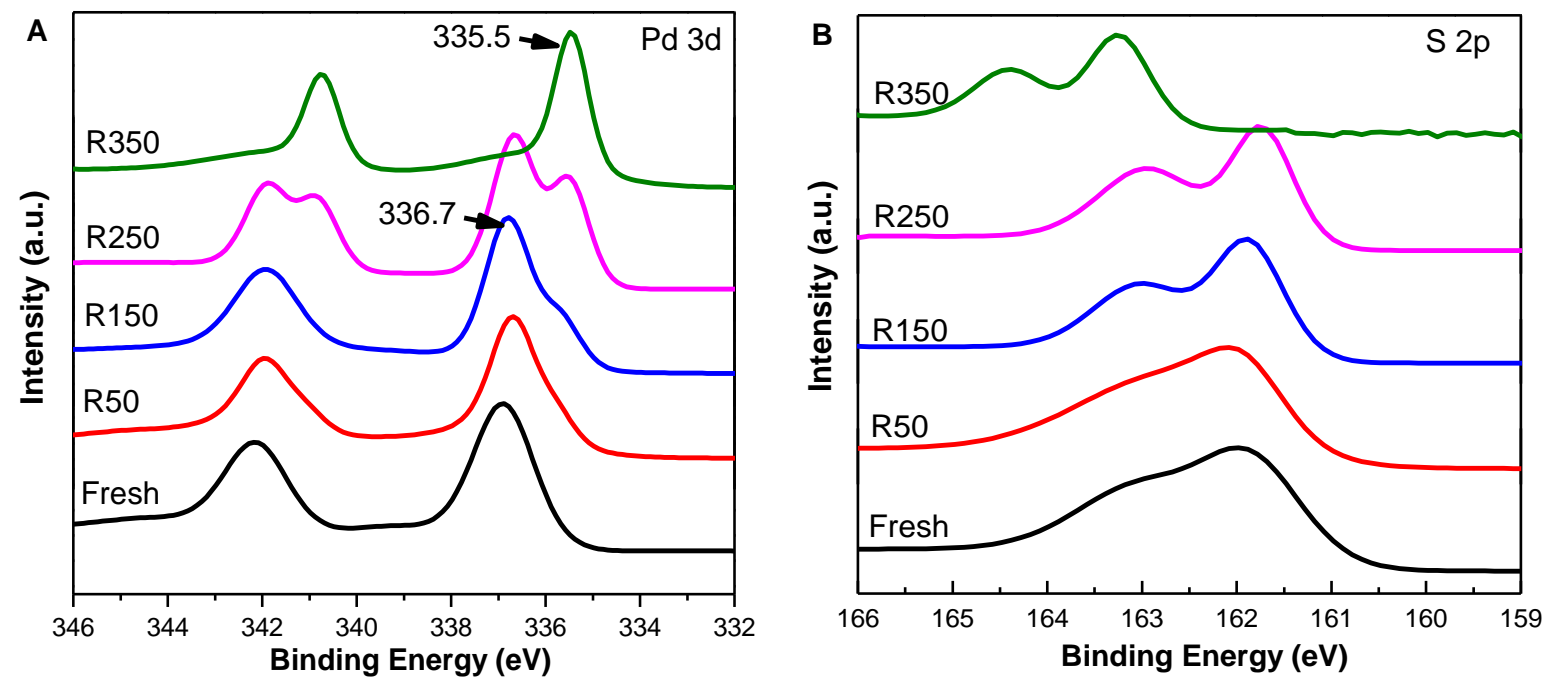

Figure 6. XP spectra of $P d 3 d(A)$ and $S 2 p(B)$ regions.

\section{Insights from X-ray absorption spectroscopy}

To better understand the structure-performance relationship for palladium sulfide, $\mathrm{X}$-ray absorption spectroscopy measurements were conducted. The Pd K edge X-ray Absorption Near-Edge Structure (XANES) of fresh palladium sulfide (i.e., unreduced), R350 and a Pd reference foil is presented in Figure 7. There is a difference between the absorption edges of fresh sample and R350, and the later appears more similar to that of Pd foil, which would imply that the oxidation state in both cases is similar. This would appear to be consistent with XPS measurements, suggesting the Pd oxidation state was close to $\mathrm{Pd}^{0}$. Moreover, it is worth noting that there is a clear change of white line owing to $s-p-d$ hybridization. ${ }^{[59]}$ Based on the reported, a less intense white line for palladium sulfides corresponds to more $\mathrm{d}$-electrons with respect to the Pd foil, ${ }^{[60]}$ which is in accordance with XPS analysis. Additionally, the presence of continuum resonance (CR) in the range of $24385-24390 \mathrm{eV}$, associated with $4 \mathrm{f} \mathrm{Pd-like}$ states ${ }^{[61,62]}$ contributes to the differences between the spectrum of palladium sulfides and Pd foil. With respect to the reference sample, a small shift of CR toward low energy is visible in the palladium sulfides, indicating the increase of the Pd-Pd distance. ${ }^{[63]}$ This is most likely ascribed to the introduction of $\mathrm{S}$ atoms. 


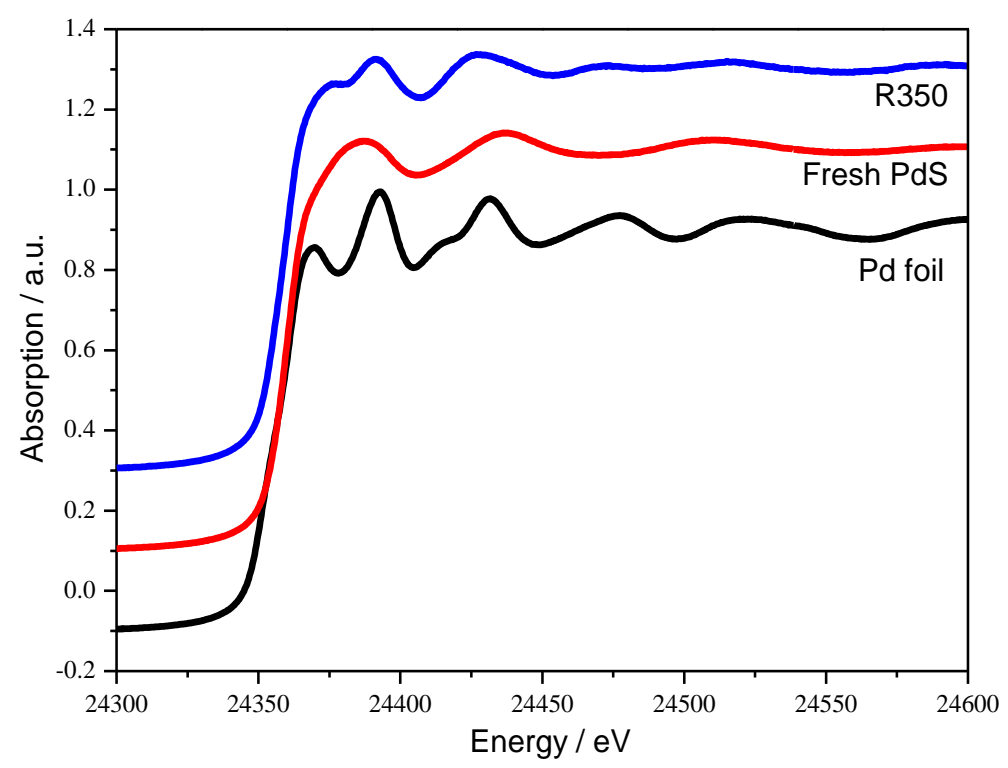

Figure 7. Normalized Pd K edge XANES spectra for fresh palladium sulfide (red), R350 sample (blue) and reference Pd foil (black).

Figure 8 illustrates the $k^{2}$-Weighted Pd K-edge EXAFS oscillations $(\mathrm{A})$ and the corresponding Fourier transforms (B) to give detailed insight into the atomic arrangement of $\mathrm{Pd}$ atoms for both samples. The fitting curves for $\chi^{2}(k)$ data (dashed line in Figure 8A) fit the experimental data for both fresh and R350 samples well up to $c a$. $15 \AA^{-1}$. As presented in R space (Figure $8 \mathrm{~B}$ ), two characteristic peaks were observed in the range of $0.12-0.30 \mathrm{~nm}$ ascribed to the scattering of $\mathrm{Pd}-\mathrm{S}$ and $\mathrm{Pd}-\mathrm{Pd}$ atomic pairs. Furthermore, the fitting for the Fourier-filtered spectrum were performed by considering the contributions of $\mathrm{Pd}-\mathrm{S}$ and $\mathrm{Pd}-\mathrm{Pd}$ shells. The quantitative parameters of the nearest coordination number $(N)$, atomic distance $(r)$, the difference in the threshold energy $(\Delta E)$ and Debye-Waller factor $(\sigma)$ are summarized in Table 3. For the fresh sample, only Pd-S scattering contributions were found with an atomic distance of $0.232 \mathrm{~nm}$ and a coordination number of $c a$. 3.5. Any attempt to include PdPd scattering contributions at longer atomic distance decreased the quality of the fit. For R350 sample, contributions from both Pd-Pd and Pd-S scatterings were present. The shortest atomic distance was associated with a Pd-S interaction $(0.230 \mathrm{~nm}$, coordination number $c a .1)$, consistent with the results of the $k^{2}$-Weighted S K-edge EXAFS (Figure S5). There were, however, more Pd-Pd interactions (coordination number ca. 3) but with at a larger atomic distance of $0.279 \mathrm{~nm}$. The atomic distance for the Pd-Pd interaction in the reference foil was found to be shorter at only $0.275 \mathrm{~nm}$. The Pd-S and Pd$\mathrm{Pd}$ interatomic distances measured in this work are comparable to those determined previously by Murayama et al. ${ }^{[64]}$ by EXAFS. In that work, Pd-S and Pd-Pd distances of 0.233 and $0.279 \mathrm{~nm}$, respectively, were reported for Pd clusters containing thiolate ligands. Similarly, the interatomic distances found here fit within the range determined experimentally by crystallography ${ }^{[65]}$ and by DFT 
calculations ${ }^{[66]}$ for the $\mathrm{Pd}_{4} \mathrm{~S}$ structure, suggesting that $\mathrm{Pd}$ atoms in $\mathrm{Pd}_{4} \mathrm{~S}$ are subjected to geometric effects/site isolation, relative to $\mathrm{Pd}$ atoms within nanoparticles. The 3D models (Figure $8 \mathrm{C}$ and D) confirm this conclusion that $\mathrm{Pd}$ atoms within $\mathrm{Pd}_{4} \mathrm{~S}$ possess exclusively $\mathrm{S}$ atoms as surface neighbours.
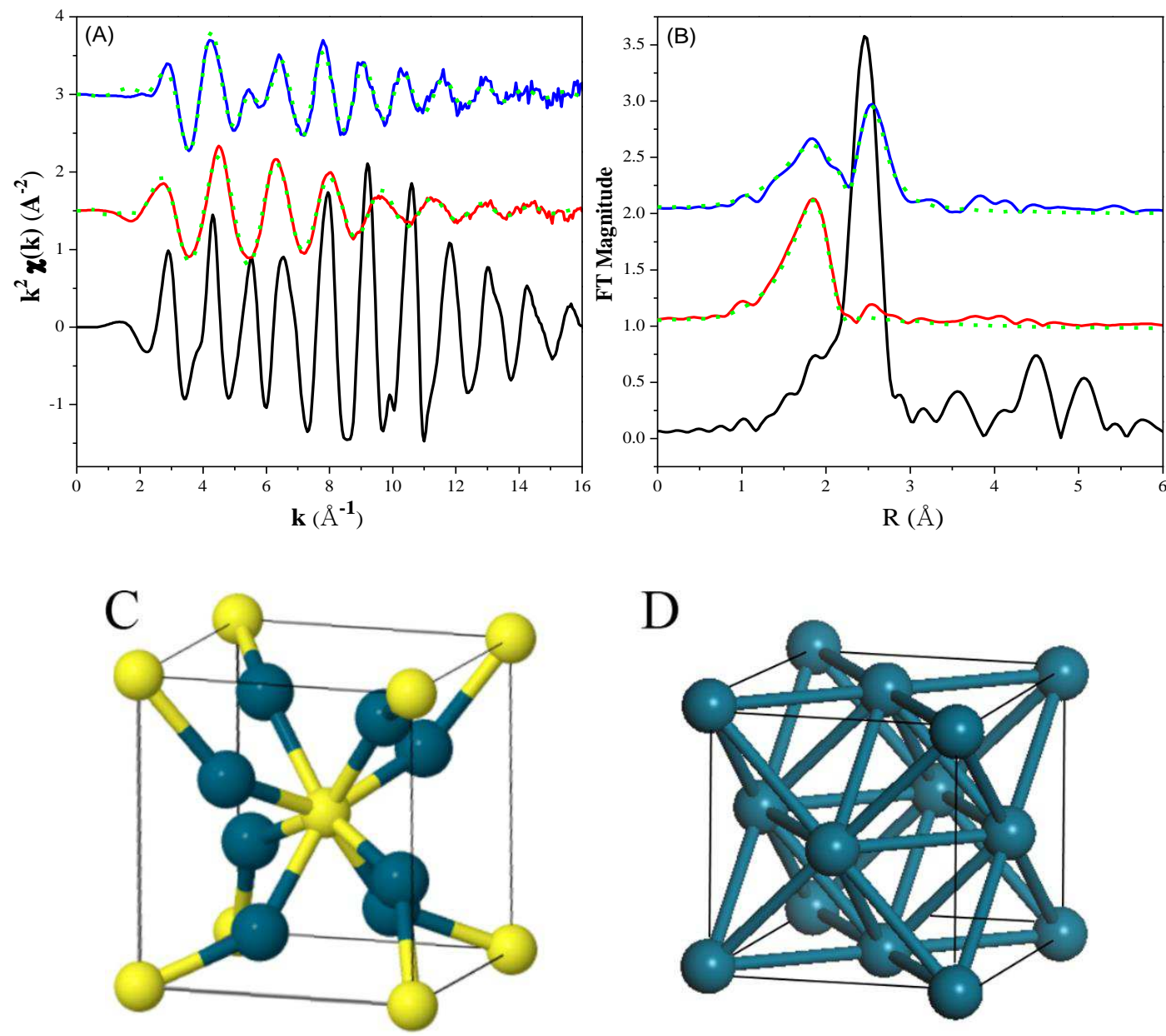

Figure 8. (A) $k^{2}$-Weighted Pd K-edge EXAFS oscillations and (B) Fourier transforms spectra of fresh palladium sulfide (red), R350 sample (blue) and reference Pd foil (black). Dotted lines represent the best fitting curves in the EXAFS analysis. 3D structure of (C) $\mathrm{Pd}_{4} \mathrm{~S}$ and (D) $\mathrm{Pd}$ metal.

Table 3. EXAFS parameters fitted for fresh PdS and R350 samples

\begin{tabular}{cccccc}
\hline Sample & Shell & $\mathbf{N}^{\mathrm{a}}$ & $\mathrm{r}^{\mathrm{b}}(\mathrm{nm})$ & $\Delta \mathrm{E}^{\mathrm{c}}(\mathrm{eV})$ & $\boldsymbol{\sigma}^{\mathrm{d}}$ \\
\hline PdS & $\mathrm{Pd}-\mathrm{S}$ & $3.47 \pm 0.06$ & $0.232 \pm 0.003$ & $1.35 \pm 0.40$ & $0.0057 \pm 0.0004$ \\
$\mathrm{R} 350$ & $\mathrm{Pd}-\mathrm{S}$ & $0.978 \pm 0.17$ & $0.230 \pm 0.001$ & $-1.46 \pm 0.40$ & $0.0054 \pm 0.0016$ \\
& $\mathrm{Pd}-\mathrm{Pd}$ & $2.978 \pm 0.37$ & $0.279 \pm 0.005$ & $-1.46 \pm 0.40$ & $0.0081 \pm 0.0008$
\end{tabular}




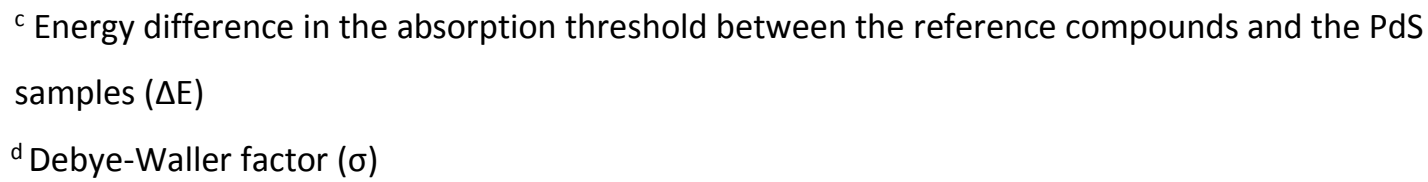

\section{Stability testing}

To demonstrate the exceptional stability of catalysts while operating at high conversion, time-on-stream analysis for the four PdS catalysts was conducted under non-competitive conditions (Figure 9). 83\% selectivity to ethene was observed for R350 at 100\% acetylene conversion without significant shift in activity or product selectivity during the $50 \mathrm{~h}$ reaction. A slight decrease of selectivity from 81 to $77 \%$ was found in R250, and a more significant loss for R150 (from 79 to 65\%) and R50 (from 79 to 54\%) was observed. Furthermore, in order to extend these tests to more industrial-like conditions, the stability test over R350 was also performed in mixed alkyne/alkene feeds (Figure S3). During $50 \mathrm{~h}$ on stream, the activity and selectivity essentially remained constant (100 and $90 \%$, respectively) thus confirming the stable performance for R350 catalyst.

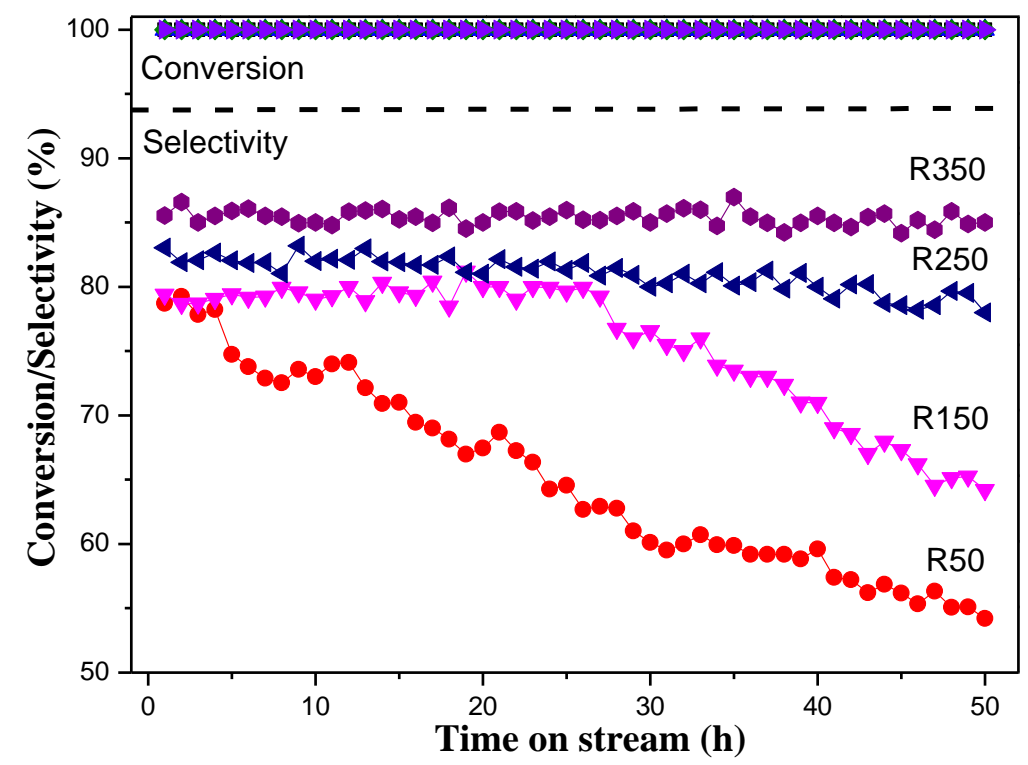

Figure 9. Acetylene conversion and selectivity versus time on stream over the PdS catalysts (GHSV: 800,000 $\mathrm{h}^{-1}$ at $\left.250^{\circ} \mathrm{C}\right)$.

It is well known that changes of catalyst structures and deposition of carbon result in deactivation of hydrogenation catalysts. In this work, the structural stability of PdS samples was confirmed by XRD and HRTEM with good agreement between the fresh and used PdS samples (Figure S1, S3 and S4). To compare the extent of accumulation of any carbonaceous residues, carbon contents were quantified after reaction using TPO-MS data and the values for R50, R150, R250 and R350 were 4.7, 2.4, 1.3, and $1.2 \%$ of the catalyst weight, respectively. Moreover, as shown in Figure 10 , the $\mathrm{CO}_{2}$ evolution profile for PdS samples occurred at different temperature, corresponding to several types of coke species. The 
peak located in the range of $250-300^{\circ} \mathrm{C}$ is attributed to unstructured carbon, which does not affect the reaction even though they may be in contact with the metal particles since the combustion is most readily affected. $[67,68]$ The second peak $\left(300-450^{\circ} \mathrm{C}\right)$ can be attributed to the combustion of amorphous coke, a precursor of graphitic carbon with a structure of $\mathrm{C}_{x} \mathrm{H}_{y}$, the accumulation of which provokes considerable steric hindrance, reducing the availability of hydrogen and/or acetylene. ${ }^{[68]}$ Compared with R50 catalyst, the peak area of amorphous coke on R350 is 70\% less and the peak is shifted to lower temperature, indicating the preferable resistance against carbonaceous build up over this sample thus explaining its superior stability.
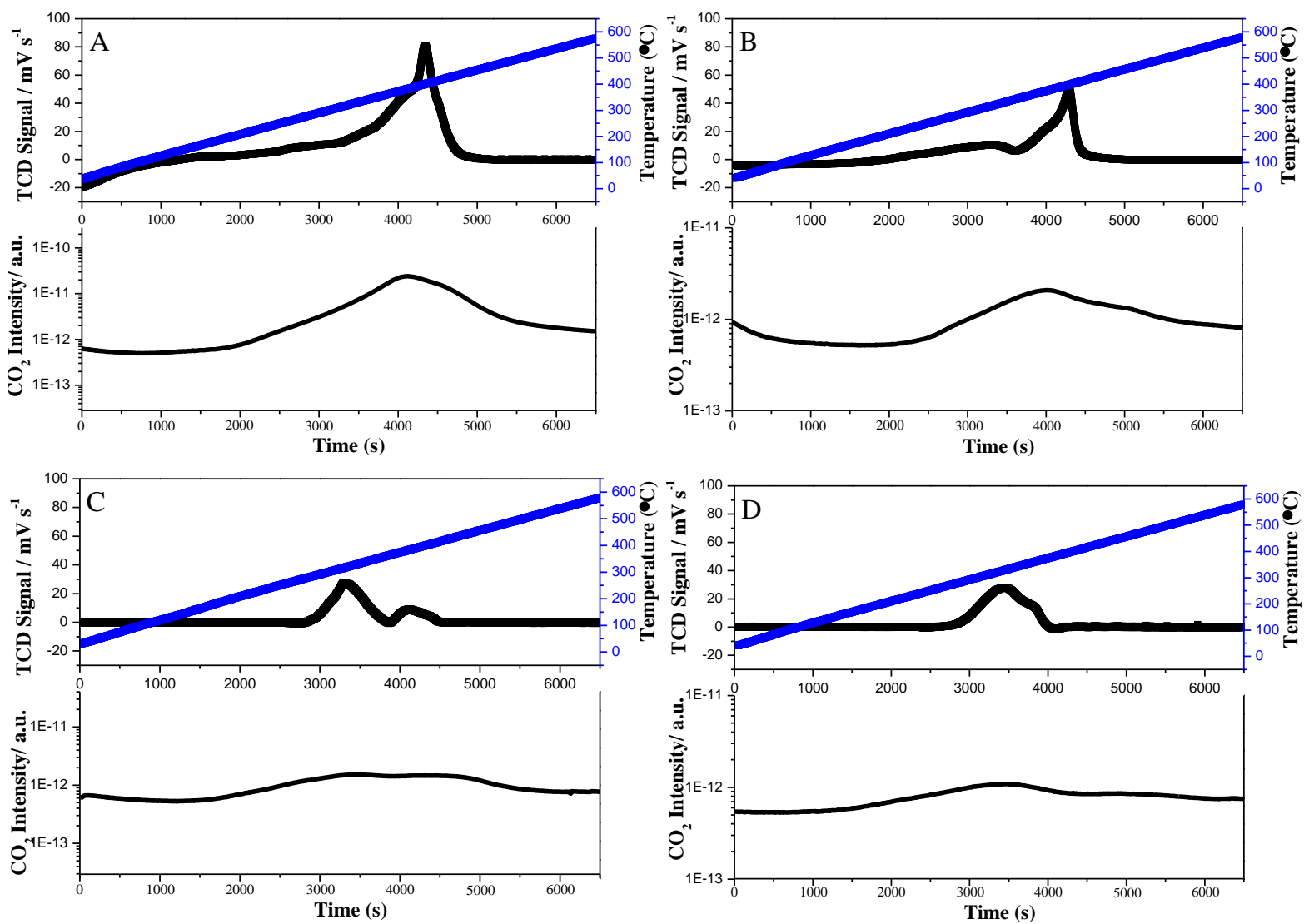

Figure 10. TPO profiles (top) and corresponding MS profiles (bottom) for (A) used R50, (B) used R150, (C) used R250 and (D) used R350 after $50 \mathrm{~h}$ test in the acetylene/hydrogen feed.

\section{Discussion}

\section{Evolution of the palladium sulfide phase}

The fresh palladium sulfide material used in this work is amorphous and has a structure which is largely dominated by Pd-S interactions (Table 3). Upon heating in a hydrogen containing atmosphere, the sample undergoes significant changes in terms of the composition, phase, crystallinity and surface area (Table 2). The extent to which these occur depend greatly on reduction temperature. At low 
temperature $\left(\approx 50^{\circ} \mathrm{C}\right)$, it is clear that hydrogen interacts with the palladium sulfide, perhaps by forming a hydride type phase as previously reported. ${ }^{[50]}$ However, this results in only a minor change in crystallinity and composition. Increasing the reduction temperature to $150^{\circ} \mathrm{C}$ sees the onset of sulfur loss as $\mathrm{H}_{2} \mathrm{~S}$ or $\mathrm{SO}_{2}$ (Figure $2 \mathrm{~A}$ ) from the surface, consistent with a shift in the composition measured by EDX (Table 2). At this temperature, the sample becomes less amorphous and XRD/TEM suggest a mixture of phases ( $\mathrm{PdS}$ and $\mathrm{Pd}_{16} \mathrm{~S}_{7}$ ) (Figures 3 and 4). Once the reduction temperature reaches $250^{\circ} \mathrm{C}$, sulfur is predominantly lost as $\mathrm{H}_{2} \mathrm{~S}$ (Figure $2 \mathrm{~A}$ ). XRD suggests a gradual shift in the phase composition from a sulfur rich $\mathrm{PdS}$ phase to a sulfur lean $\mathrm{Pd}_{4} \mathrm{~S}$ phase (via $\mathrm{Pd}_{16} \mathrm{~S}_{7}$ as an intermediate).

Given that by $250^{\circ} \mathrm{C}$, considerable particle growth has occurred, it seems relevant to consider the transformation on a macroscopic scale. Hydrogen and sulfur must diffuse through the structure until they meet and react. In principle, this could occur by $S$ atoms migrating from the bulk to the surface. However, given that palladium sulfides are known to be permeable to hydrogen, ${ }^{[69,70]}$ it seems more likely that hydrogen diffuses from the surface into the bulk to find a $S$ atom. That being the case, one would expect that sulfur atoms are abstracted from surface and near surface sites first. This would result in the sulfur deficient phase tends to be on the surface and near surface region relative to the bulk of a particle. Reduction at $350^{\circ} \mathrm{C}$ seems to provide the system with sufficient energy to convert to a largely pure phase (Figure 3). Only a small fraction (5.4\%) of the sample remains as PdS according to XRD. This could be because the core of larger particles is still rich in sulfur, however, if that were the case then the intermediate $\mathrm{Pd}_{16} \mathrm{~S}_{7}$ phase should be observable. It therefore seems more likely that there is a small amount of PdS which is more thermally stable.

\section{Implications of the phase transformation on activity}

Pre-reduced samples were used to collect the catalytic data presented in Figure 1. This is significant as reaction data was collected while increasing the temperature from 50 to $250^{\circ} \mathrm{C}$. In other words, R50 and R150 samples would be expected to continue to undergo change during reaction as the feed gas contains hydrogen. As a result, the only data points which can be directly correlated with characterisation results would be those collected at a reaction temperature of $50^{\circ} \mathrm{C}$, assuming that R50 and R150 samples undergo no further change under reactions conditions. In terms of activity, as the amount of $\mathrm{Pd}_{4} \mathrm{~S}$ increases, the activity also increases (i.e., R350 is most active at $50^{\circ} \mathrm{C}$ ) despite particle growth and a corresponding decrease in the relative number of surface sites. However, it was worth noting that the phase composition gradually shifted from a palladium-lean PdS phase to a palladium-rich $\mathrm{Pd}_{4} \mathrm{~S}$ phase (Table 2), and the oxidation state of $\mathrm{Pd}$ changed from positive to a near neutral charge (Figure 6 and 7) with an increase in the reduction temperature, which was similar with the properties of Pd metal/alloy. ${ }^{[58]}$ Based on the above results, it is believed that sample reduced at 
$350^{\circ} \mathrm{C}$ possesses a greater ability to activate hydrogen than R50, R150 and R250 due to this metallic characteristic ${ }^{[47,69]}$ and consequently contributed to the enhanced activity.

\section{Implications of the phase transformation on selectivity}

From Figure 1 it would be tempting to assume that $\mathrm{PdS}$ and $\mathrm{Pd}_{16} \mathrm{~S}_{7}$ phases are more selective than $\mathrm{Pd}_{4} \mathrm{~S}$. However establishing clear links between palladium sulfide phase and selectivity at $50^{\circ} \mathrm{C}$ is not trivial since ethylene selectivity is strongly influenced by conversion. ${ }^{[6]}$ This is because overhydrogenation typically occurs more readily at high acetylene conversion/low acetylene coverage. At reaction temperatures above $50^{\circ} \mathrm{C}$, the performance of $\mathrm{R} 50, \mathrm{R} 150, \mathrm{R} 250$ and $\mathrm{R} 350$ samples become more equivalent. Indeed, all samples display ethylene selectivity of $c a .80 \%$ at $100 \%$ conversion at $250^{\circ} \mathrm{C}$ (Figure 1). Given that the selectivity of the R350 sample can be directly related with the presence of the $\mathrm{Pd}_{4} \mathrm{~S}$ phase, it seems reasonable to assume that the same phase dominates the surface zones of the remaining samples when under reaction at these higher temperatures. In other words, sulfur is initially stripped away from the surface and near-surface layers, during exposure to hydrogen at the elevated temperatures necessary to form $\mathrm{Pd}_{4} \mathrm{~S}$.

XAS results provided detailed information about the environment around Pd atoms in R350 sample (Table 3 and Figure 8). The results are largely in agreement with the crystal structure reported for the $\mathrm{Pd}_{4} \mathrm{~S}$ phase ${ }^{[65]}$ with the nearest neighbour for a Pd atom being a single sulfur atom at $0.230 \mathrm{~nm}$ (Table 3). Pd-Pd interactions are more prominent but, importantly, are at an elongated distance $(0.279 \mathrm{~nm})$ relative to monometallic Pd $(0.275 \mathrm{~nm}) .{ }^{[70]}$ DFT calculation and experiment results in the literature indicate that the larger Pd-Pd interatomic distance in $\mathrm{Pd}_{4} \mathrm{~S}$, relative to $\mathrm{Pd}$ nanoparticles acts partly to create site isolation (no larger than $\mathrm{Pd} 3$ ), which is beneficial for improving alkyne hydrogenation performance. ${ }^{[27-30,71]}$ In this work, a similar effect is thought to be responsible, in part, for the exceptional selectivity of the $\mathrm{Pd}_{4} \mathrm{~S}$ phase, compared with monometallic Pd catalysts. However, samples with PdS structure (R50, R150 and R250) show lower selectivity of ethylene even though they, in principle, offer better site isolation (Figure 8), indicating that the small ensemble size (geometric effect) cannot be considered as the sole reason for the differences in the catalytic selectivity observed for PdS samples.

TPR-MS results show that thermal treatment in hydrogen strips sulfur from palladium sulfide during the reduction process (Figure 2). The sulphur, as the neighbour on the surface of $\mathrm{Pd}_{4} \mathrm{~S}$ catalyst, perturbs the electronic structure of $\mathrm{Pd}$, leading to the valence state of $\mathrm{Pd}$ changing from a more positive charge to a near neutral charge, consistent with XPS and EXAFS analysis. Therefore, in contrast to R50, R150 and R250 with PdS structure, the surface Pd atoms in the $\mathrm{Pd}_{4} S$ sample (R350) possesses 
much higher electron density. Based on reports in literature ${ }^{[72,73]}$, negatively-charged Pd favours the desorption of ethylene, thus improving the selectivity.

In summary, a possible mechanism considering site isolation and the role of lost sulfur over $\mathrm{Pd}_{4} \mathrm{~S}$ catalysts is proposed. In detail, in the term of the samples with small ensemble size (no larger than $\mathrm{Pd} 3), \mathrm{C}_{2} \mathrm{H}_{2}$ prefers to coordinate on two adjacent $\mathrm{Pd}$ atoms, facilitating formation of $\mathrm{C}_{2} \mathrm{H}_{4}$ through an ethylene-like $\mathrm{C}_{2} \mathrm{H}_{3} \mathrm{Pd}$ intermediate, whereas ethylene adsorbs on a $\mathrm{Pd}$ atom in $\pi$ configuration with a low adsorption energy. ${ }^{[30]}$ Moreover, the $\mathrm{S}$ atoms as the neighbour in $\mathrm{Pd}_{4} \mathrm{~S}$ samples perturb the $\mathrm{Pd}$ electronic state, resulting in the relative increase of electron density of $\mathrm{Pd}$, and consequence further decreases ethylene desorption from the $\mathrm{Pd}_{4} \mathrm{~S}$ surface, contributing to the enhanced selectivity of ethylene. More importantly, the catalytic performance of R350 sample maps on well to that previously reported for a nano-sized $\mathrm{Pd}_{4} \mathrm{~S}$ supported on carbon nanofibers. ${ }^{[49,50]}$ This report therefore suggests that detailed characterisation of bulk phase materials can be useful for establishing links with analogous nano-sized particles which are challenging to characterise given their extremely small size.

\section{Conclusions}

The transformation of a palladium sulfide sample during thermal treatments has been assessed in detail. During reduction at temperatures of $150^{\circ} \mathrm{C}$ or higher, sulfur is lost to the gas phase, mainly as $\mathrm{H}_{2} \mathrm{~S}$. Concurrently, the sample undergoes a phase change from a sulfur rich PdS phase to a sulfur lean $\mathrm{Pd}_{4} \mathrm{~S}$ phase (via the $\mathrm{Pd}_{16} \mathrm{~S}_{7}$ phase as an intermediate). The extent to which this transformation occurs depends on temperature. Reduction at $250^{\circ} \mathrm{C}$ produces a material, which contains simultaneously these three phases with some $\mathrm{Pd}_{4} \mathrm{~S}$ phase is located at the surface. Reduction at $350^{\circ} \mathrm{C}$ almost exclusively converts the sample to the $\mathrm{Pd}_{4} \mathrm{~S}$ phase. Samples which contain a significant portion of the $\mathrm{Pd}_{4} \mathrm{~S}$ phase offer excellent activity and selectivity for acetylene hydrogenation even under competitive conditions. The selectivity is in part attributed to a site isolation effect brought about as a result of the crystal structure of $\mathrm{Pd}_{4} \mathrm{~S}$, but also due to changes in adsorption desorption energetic brought about by changes to the Pd electronic state. No signs of deactivation or significant deposition of carbon were observed over $\mathrm{Pd}_{4} \mathrm{~S}$ sample after $50 \mathrm{~h}$ on stream.

\section{Acknowledgements}

We thank Diamond Light Source for beamline access B18 (SP15151-5) and are grateful to the expertise and help provided by Dr Emma Gibson (UK Catalysis Hub, Harwell) and Diego Gianolio (Beamline Scientist on B18) whilst data collecting. XPS data collection was performed at the EPSRC National Facility for XPS ('HarwellXPS'), operated by Cardiff University and UCL, under contract No. PR16195. 
We would also like to thank Prof. Philip R. Davies for helpful discussions on XPS data analysis. This work was partly supported by the National Key Research and Development Program of China (2016YFB0301601), National Natural Science Foundation of China.

\section{References}

[1] A. Borodziński, G. C. Bond, Catal. Rev. 2006, 48, 91-144.

[2] A. Borodziński, G. C. Bond, Catal. Rev. 2008, 50, 379-469.

[3] S. A. Nikolaev, I. L. N. Zanaveskin, V. V Smirnov, V. A. Averyanov, K. I. Zanaveskin, Russ. Chem. Rev. 2009, 78, 231-247.

[4] D. B. Tiedtke, T. T. P. Cheung, J. Leger, S. A. Zisman, J. J. Bergmeister and G. A. Delzer in: $13^{\text {th }}$ Ethlyene Producers Conference, 2001, 10, 1-21.

[5] S. Asplund, J. Catal. 1996, 158, 267.

[6] A. J. McCue, J. A. Anderson, Front. Chem. Sci. Eng. 2015, 9, 142-153.

[7] M. M. Johnson, D. W. Walker, G. P. Nowack, US Patent 4404124, 1983.

[8] D. Teschner, J. Borsodi, A. Wootsch, Z. Revay, M. Hävecker, A. Knop-Gericke, S. D. Jackson, R. Schlögl, Science 2008, 320, 86-89.

[9] M. García-Mota, B. Bridier, J. Pérez-Ramírez, N. López, J. Catal. 2010, 273, 92-102.

[10] B. Yang, R. Burch, C. Hardacre, G. Headdock, P. Hu, J. Catal. 2013, 305, 264-276.

[11] N. A. Khan, S. Shaikhutdinov, H. J. Freund, Catal. Letters. 2006, 108, 159-164.

[12] W. Ludwig, A. Savara, K. H. Dostert, S. Schauermann, J. Catal. 2011, 284, 148-156.

[13] F. Viñes, C. Loschen, F. Illas, K. M. Neyman, J. Catal. 2009, 266, 59-63.

[14] F. Studt, F. Abild-Pedersen, T. Bligaard, R. Z. Sorensen, C. H. Christensen, J. K. Norskov, Science 2008, 320, 1320-1322.

[15] Y. Liu, J. Zhao, Y. He, J. Feng, T. Wu, D. Li, J. Catal. 2017, 348, 135-145.

[16] Y. He, Y Liu, P. Yang, Y. Du, J. Feng, X. Cao, D. Li, J. Catal. 2015, 330, 61-70.

[17] Y. Zhang, W. Diao, J. R. Monnier, C. T. Williams, Catal. Sci. Technol. 2015, 5, 4123-4132.

[18] J. Feng, Y. Liu, M. Yin, Y. He, J. Zhao, J. Sun, D. Li, J. Catal. 2016, 344, 854-864.

[19] A. J. McCue, R. T. Baker, J. A. Anderson, Faraday Discuss. 2016, 188, 499-523.

[20] Y. N. Liu, J. T. Feng, Y. F. He, J. H. Sun, D. Q. Li, Catal. Sci. \& Technol. 2015, 5, 1231-1240.

[21] A. J. McCue, C. J. McRitchie, A. M. Shepherd, J. A. Anderson, J. Catal. 2014, 319, 127-135.

[22] A. J. McCue, J. A. Anderson, J. Catal. 2015, 329, 538-546.

[23] A. J. McCue, A. Gibson, J. A. Anderson, Chem. Eng. J. 2016, 285, 384-391.

[24] A. J. McCue, A. M. Shepherd, J. A. Anderson, Catal. Sci. Technol. 2015, 5, 2880-2890.

[25] Q. Jin, Y. He, M. Miao, C. Guan, Y. Du, J. Feng, D. Li, Appl. Catal. A: Gen., 2015, 500, 3-11.

[26] H. Zhou, X. Yang, L. Li, X. Liu, Y. Huang, X. Pan, A. Wang, T. Zhang, ACS Catal. 2016, 6, 1054-1061.

[27] G. Vilé, D. Albani, N. Nachtegaal, Z. Chen, D. Dontsova, M. Antonietti, N. López, J. Pérez-Ramírez, J., Angew. Chem. Int. Ed. 2015, 54, 11265-11269.

[28] J. Osswald, K. Kovnir, M. Armbrüster, R. Giedigkeit, R. E. Jentoft, U. Wild, Y. Grin, R. Schlögl, J. Catal., 2008, 258, 219-227.

[29] M. Friedrich, S. A. Villaseca, L. Szentmiklósi, D. Teschner, M. Armbrüster, Materials, 2013, 6, 2958-2977.

[30] Q. Feng, S. Zhao, Y. Wang, J. Dong, W. Chen, D. He, D. Wang, J. Yang, Y. Zhu, H. Zhu, L. Gu, Z. Li, Y. Liu, R. Yu, J. Li, Y. Li, J. Am. Chem. Soc. 2017, 139, 7294-7301.

[31] L. Shao, W. Zhang, M. Armbrüster, D. Teschner, F. Girgsdies, B. Zhang, O. Timpe, M. Friedrich, R.

R. Schlögl, D. Sheng Su, Angew. Chem. Int. Ed. 2011, 50, 10231-10235. 
[32] G. Pei, X. Liu, A. Wang, A. F. Lee, M. A. Isaacs, L. Li, X. Pan, X. Yang, X. Wang, Z. Tai, K. Wilson, T. Zhang, ACS Catal. 2015, 5, 3717-3725.

[33] G. X. Pei, X. Y. Liu, X. Yang, L. Zhang, A. Wang, L. Li, H. Wang, X. Wang, T. Zhang, ACS Catal. 2017, 7, 1491-1500.

[34] G. Kyriakou, M. B. Boucher, A. D. Jewell, E. A. Lewis, T. J. Lawton, A. E. Baber, H. E. Tierney, M. Flytzani-Stephanopoulos, E. C. H. Sykes, Science 2012, 335, 1209-1212.

[35] H. L. Tierney, A. E. Baber, J. R. Kitchin, E. C. H. Sykes, Phys. Rev. Lett. 2009, 103, 246102-1246102-4.

[36] M. B. Boucher, B. Zugic, G. Cladaras, J. Kammert, M. D. Marcinkowski, T. J. Lawton, E. C. H. Sykes, M. Flytzani-Stephanopoulos, Phys. Chem. Chem. Phys. 2013, 15, 12187-12196.

[37] F. M. McKenna, J. A. Anderson, J. Catal. 2011, 281, 231-240.

[38] F. M. McKenna, R. P. K. Wells, J. A. Anderson, Chem. Comm. 2011, 47, 2351-2353.

[39] F. M. McKenna, L. Mantarosie, R.P.K. Wells, C. Hardacre, J. A. Anderson, Catal. Sci. Technol. 2012, 2, 632-638.

[40] G. Vilé, N. Almora-Barrios, S. Mitchell, N. López, J. Pérez-Ramírez, Chem. Eur. J. 2014, 20, 59265937.

[41] D. Albani, G. Vilé, S. Mitchell, P. T. Witte, N. Almora-Barrios, R. Verel, N. López, J. Pérez-Ramírez, Catal. Sci. Technol. 2016, 6, 1621-1631.

[42] A. J. McCue, F. M. McKenna, J. Anderson, Catal. Sci. Technol. 2015, 5, 2449-2459.

[43] G. Vilé, B. Bridier, J. Wichert, J. Pérez-Ramírez, Angew. Chem. Int. Ed. 2012, 51, 8620-8623.

[44] J. Carrasco, G. Vilé, D. Fernández-Torre, R. Pérez, J. Pérez-Ramírez, J. Phys. Chem. C, 2014, 118, 5352-5360.

[45] G. Vilé, P. Dähler, J. Vecchietti, M. Baltanás, S. Collins, M. Calatayud, A. Bonivardi, J. PérezRamírez, J. Catal. 2015, 324, 69-78.

[46] D. Albani, M. Capdevilla-Cortada, G. Vilé, S. Mitchell, O. Martin, N. López, J. Pérez-Ramírez, Angew. Chem. 2017, 56, 10755-10760.

[47] B. Bachiller-Baeza, A. Iglesias-Juez, E. Castillejos-López, A. Guerrero-Ruiz, M. Di Michiel, M. Fernández-García, I. Rodríguez-Ramos, ACS Catal. 2015, 5, 5235-5241.

[48] B. Bachiller-Baeza, J. Peña-Bahamonde, E. Castillejos, A. Guerrero-Ruiz, I. Rodríguez-Ramos Catal. Today, 2015, 249, 63-71.

[49] A. J. McCue, A. Guerrero-Ruiz, I. Rodríguez-Ramos, J. A. Anderson, J. Catal. 2016, 340, 10-16.

[50] A. J. McCue, A. Guerrero-Ruiz, C. Ramirez-Barria, I. Rodríguez-Ramos, J. A. Anderson, J. Catal.

2017, 355, 40-52.

[51] A. J. McCue, J. A. Anderson, Catal. Sci. Technol. 2014, 4, 272-294.

[52] L. B. McCusker, R. B. Von Dreele, D. E. Cox, D. LoueĖr and P. Scardi, J. Appl. Cryst. 1999, 32, 3650.

[53] Y. F. He, J. T. Feng, Y. Y. Du and D. Q. Li, ACS Catal., 2012,2, 1703.

[54] Y. F. He, L. L. Liang, Y. N. Liu, J. T. Feng, C. Ma and D. Q. Li,J. Catal., 2014, 309, 166.

[55] E. W. Shin, J. K. Kang, W. J. Kim, J. D. Park and S. H. Moon, Appl. Catal., A, 2002, 223, 161

[56] F. Grønvold, E. Røst, Acta Chem. Scand., 1952, 10, 1620-1634.

[57] Q. Zhang, W. Xu, X. Li, D. Jiang, Y. Xiang, J. Wang, J. Cen, S. Romano, J. Ni, Appl. Catal. A Gen. 2015, 497, 17-21.

[58] V. V. Signh, U. Kumar, S. N. Tripathi, A. K. Singh, Dalton Trans. 2014, 43, 12555-12563.

[59] Feng Liu, Dominik Wechsler, Peng Zhang, Chemical Physics Letters 461 (2008) 254-259.

[60] P. Zhang and T. K. Sham, Appl. Phys. Lett., 4 (2002) 81.

[61] M. Fernández-García, Catal. Rev. Sci. Eng. 44 (2002) 59.

[62] M. Fernández-García, A. Iglesias-Juez, A. Martínez-Arias, A. B. Hungría, J. A. Anderson, J. C. Conesa, and J. Soria, J. Catal. 221 (2004) 594-600

[63] A. Iglesias-Juez, A. Martínez-Arias, M. A. Newton, S. G. Fiddy and M. Fernández-García, Chem. Commun., 2005, 4092-4094.

[64] H. Murayama, N. Ichikuni, Y. Negishi, T. Nagata, T. Tsukuda, Chem. Phys. Lett. 2003, 376, 26-32. 
[65] F. Grønvold, E. Røst, Acta Cryst. 1962, 15, 11-13.

[66] J. B. Miller, D. R. Alfonso, B. H. Howard, C. P. O-Brien, B. D. Morreale, J. Phys. Chem. C 2009, 119, 18800-18806.

[67] C. Ma, Y. Y. Du, J. T. Feng, X. Z. Cao, J. Yang, D. Q. Li, J. Catal. 2014, 317, 263-271.

[68] Y. Azizi, C. Petit, V. Pitchon, J. Catal. 2008, 256, 338-344.

[69] B. Radha, G. U. Kulkarni, Adv. Funct. Mater. 2010, 20, 879-884.

[70] C. N. Rao, K. K. Rao, Ca. J. Phys. 1964, 42, 1336-1342..

[71] Y. Luo, S. A. Villaseca, M. Friedrich, D. Teschner, A. Knop-Gericke, M. Armbrùster, J. Catal. 2016, $338,265-272$.

[72] W. J. Kim, I. Y. Ahn, J. H. Lee and S. H. Moon, Catal. Commun., 2012, 24, 52.

[73] E. Kim, E. W. Shin, C. W. Bark, I. Chang, W. J. Yoo and W. J. Kim, Appl. Catal., A, 2014, 471, 80 